
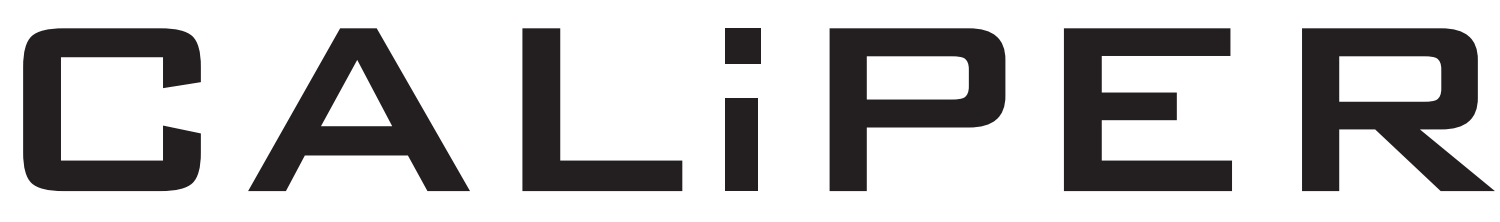

BENCHMARK REPLRT

JANUARY 2009

\title{
Performance of T12 and T8 Fluorescent Lamps and Troffers and LED Linear Replacement Lamps
}




\title{
DOE SSL Commercially Available LED Product Evaluation and Reporting Program \\ NO COMMERCI AL USE POLICY
}

The U.S. Department of Energy (DOE) is a federal agency working in the public interest. Published information from the DOE SSL CALiPER Program, including test reports, technical information, and summaries, is intended solely for the benefit of the public, in order to help buyers, specifiers of new SSL products, testing laboratories, energy experts, energy program managers, regulators, and others make informed choices and decisions about SSL products and related technologies.

Such information may not be used in advertising, to promote a company's product or service, or to characterize a competitor's product or service. This policy precludes any commercial use of any DOE SSL CALiPER Program published information in any form without DOE's expressed written permission.

\section{DISCLAIMER}

This report was prepared as an account of work sponsored by an agency of the United States Government. Neither the United States Government nor any agency thereof, nor Battelle Memorial Institute, nor any of their employees, makes any warranty, express or implied, or assumes any legal liability or responsibility for the accuracy, completeness, or usefulness of any information, apparatus, product, or process disclosed, or represents that its use would not infringe privately owned rights. Reference herein to any specific commercial product, process, or service by trade name, trademark, manufacturer, or otherwise does not necessarily constitute or imply its endorsement, recommendation, or favoring by the United States Government or any agency thereof, or Battelle Memorial Institute. The views and opinions of authors expressed herein do not necessarily state or reflect those of the United States Government or any agency thereof.

\author{
PACIFIC NORTHWEST NATIONAL LABORATORY \\ operated by \\ BATTELLE \\ for the \\ UNTTED STATES DEPARTMENT OF ENERGY \\ under Contract DE-AC05-76RL01830
}

Printed in the United States of America
Available to DOE and DOE contractors from the Office of Scientific and Technical Information,
P.O. Box 62, Oak Ridge, TN 37831-0062;
ph: (865) 576-8401
fax: (865) 576-5728
email: reports@adonis.osti.gov

\author{
Available to the public from the National Technical Information Service, \\ U.S. Department of Commerce, 5285 Port Royal Rd., Springfield, VA 22161 \\ ph: (800) 553-6847 \\ fax: (703) 605-6900 \\ email: orders@ntis.fedworld.gov \\ online ordering: http://www.ntis.gov/ordering.htm
}

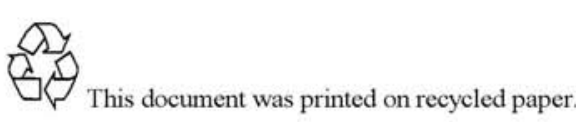

(9/2003) 


\title{
Performance of T12 and T8 Fluorescent Lamps and Troffers and LED Linear Replacement Lamps
}

CALiPER Benchmark Report

\author{
MA Myer \\ ML Paget \\ RD Lingard
}

January 2009

Prepared for

the U.S. Department of Energy

under Contract DE-AC05-76RL01830

Pacific Northwest National Laboratory

Richland, Washington 99352 


\begin{abstract}
The U.S. Department of Energy (DOE) Commercially Available LED Product Evaluation and Reporting (CALiPER) Program was established in 2006 to investigate the performance of luminaires and replacement lamps that use light-emitting diodes (LEDs). To help users better compare LED products with conventional lighting technologies, CALiPER also has performed benchmark research and testing of traditional (i.e., non-LED) lamps and fixtures. This benchmark report addresses standard 4-ft fluorescent lamps (i.e., T12 and T8) and the 2-ft by 4-ft recessed troffers in which they are commonly used. This report also examines available LED replacements for T12 and T8 fluorescent lamps and their application in fluorescent troffers. The construction and operation of linear fluorescent lamps and troffers are discussed, as well as fluorescent lamp and fixture performance, based on manufacturer data and CALiPER benchmark testing.

In addition, the report describes LED replacements for linear fluorescent lamps and compares their bare lamp and in situ performance with fluorescent benchmarks on a range of standard lighting measures, including power usage, light output and distribution, efficacy, correlated color temperature, and the color rendering index. Potential performance and application issues indicated by CALiPER testing results also are examined. CALiPER testing of currently available LED replacements for 4-ft T12 and T8 fluorescent lamps indicates that although LED linear replacement lamps are marketed as one-for-one drop-in retrofits for general fluorescent applications, their comparatively low light output could result in unacceptably low illumination levels in retrofit applications. Although there may be some niche applications in which the lower light output, superior cold-temperature operation, and potentially longer life of LED linear replacements are indicated, CALiPER testing at this time shows that LED technology is not yet ready to displace linear fluorescent lamps as replacement light sources in recessed troffers for general interior lighting.
\end{abstract}





\section{Contents}

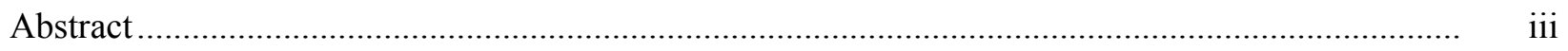

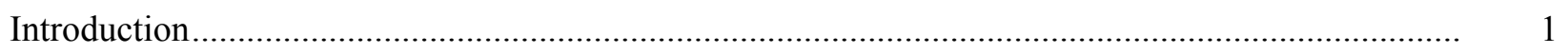

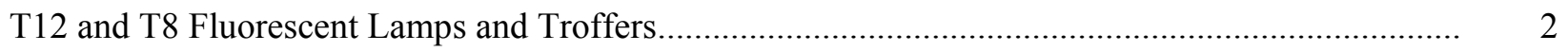

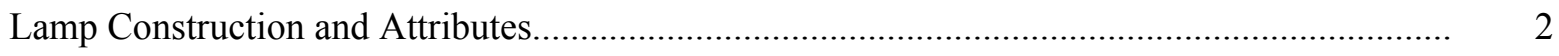

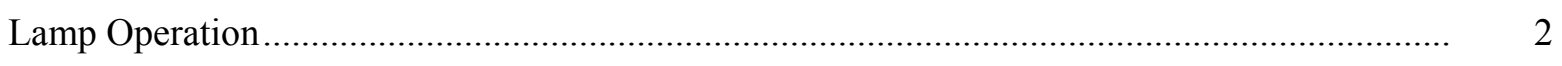

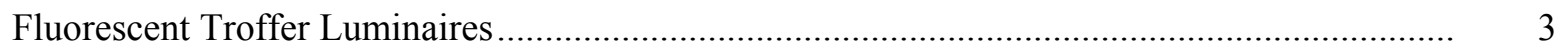

Performance of T12 and T8 Fluorescent Troffers................................................................. 5

LED Replacements for T12 and T8 Fluorescent Lamps in Troffer Luminaires .............................. 7

Performance of LED Replacements for Linear Fluorescent Lamps ............................................ 9

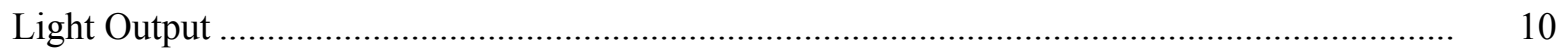

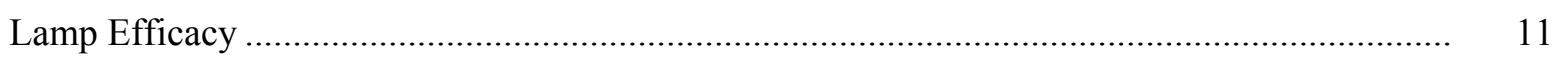

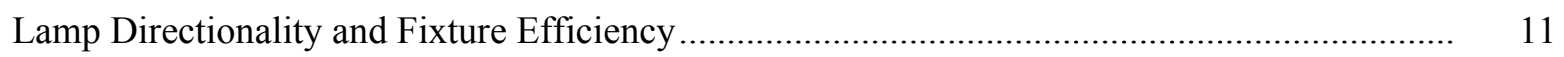

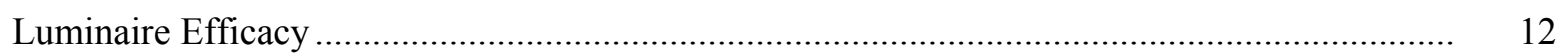

Luminaire Light Distribution and Resulting Illumination................................................... 13

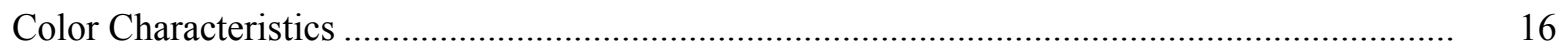

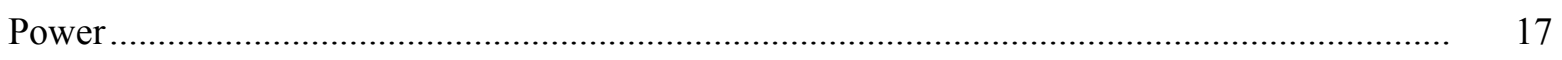

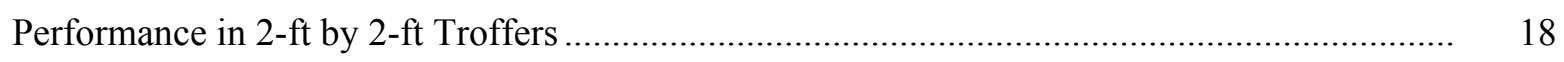

Untangling Performance Claims for LED Linear Replacement Lamps ....................................... 19

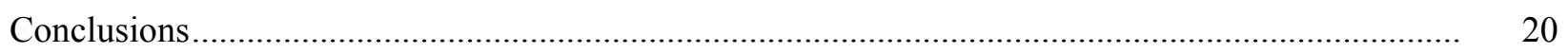

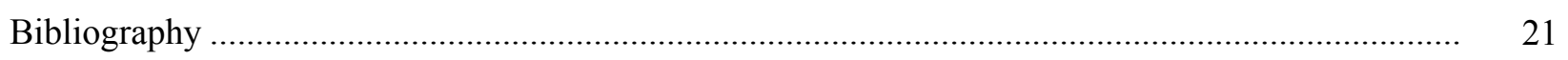

Appendix - Luminous Intensity, Zonal Lumens, and Fixture Luminance ..................................... A.1

\section{Figures}

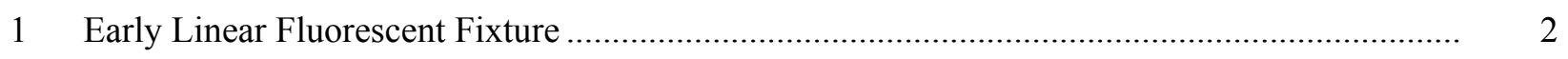

2 Lensed and Parabolic Troffer Construction ............................................................................. 4

3 Lensed and Parabolic Louver Troffer Light Distribution ..................................................... 4

$4 \quad$ Typical LED Linear Replacement Lamps ....................................................................... 8

5 Directionality of Linear Fluorescent and LED Replacement Lamps in Relation to Typical Parabolic Louver Troffer Construction .................................................................

6 Measured Light Output of 4-ft LED Linear Replacement Lamps Compared to 4-ft Linear Fluorescent Lamps

7 Measured Light Output of 4-ft Linear Fluorescent Lamps and LED Replacements Compared to Manufacturers' Reported Values

8 Measured Efficacy of 4-ft Linear Fluorescent Lamps and LED Replacements Compared to Manufacturers' Reported Values 
9 Luminaire Output versus Efficacy for 4-ft Linear Fluorescent Lamps and LED Replacements in Lensed and Parabolic Louver Troffers

10 Measured Luminous Intensity Distributions and Calculated Zonal Lumen Density Percentages for Lensed Troffer with Two 4-ft T12 Fluorescent Lamps and LED Replacements

11 Measured Luminous Intensity Distributions and Calculated Zonal Lumen Density Percentages for Parabolic Louver Troffer with Two 4-ft T8 Fluorescent Lamps and LED Replacements

12 Comparison of Measured CCT Values for Linear Fluorescent Lamps and LED Replacements

13 Chromaticity of LED Linear Replacement Lamps Plotted Against ANSI Chromaticity Specifications.

\section{Tables}

1 Manufacturer and CALiPER Benchmarks for Two-Lamp Fluorescent Parabolic Louver Troffers

2 Average Luminance Data for Parabolic Troffers................................................................... 6

3 Average Zonal Lumen Summary for Lensed and Parabolic Troffers

4. Summary of CALiPER Bare Lamp Testing for 4-ft Linear Fluorescent Lamps and LED Replacements

5 Summary of CALiPER Testing for 4-ft Linear Fluorescent Lamps and LED Replacements in Lensed and Parabolic Louver Troffers

6 Spacing Criteria: Fluorescent Versus LED Replacement Lamps .....

7 Performance of 2-ft by 2-ft LED Panels 


\section{Introduction}

Solid-state lighting (SSL) products using light-emitting diodes (LEDs) are proliferating in the lighting marketplace. Their low energy consumption, potential long life, and compact form make LEDs an attractive alternative to traditional light sources in some applications. It can be argued, however, that the marketing of SSL technology has outpaced the development and practice of using standard test procedures by which to characterize the performance of a product. Consequently, the consumer faces a rapidly increasing variety of LED luminaires and replacement lamps, along with a bewildering range of product claims - and a relative lack of information with which to accurately evaluate LED lighting products as well as compare them to traditional technologies.

To fill the gap in data on LED lighting, the U.S. Department of Energy (DOE) initiated the Commercially Available LED Product Evaluation and Reporting (CALiPER) Program in 2006. Industry standard test procedures now exist to measure the efficacy, photometric performance, and color characteristics of LED luminaires and replacement lamps. Related standard test procedures for determining LED product lifetime are nearing completion. Through independent testing laboratories, CALiPER has used these procedures to evaluate a variety of LED luminaires and replacement lamps available through common retail channels and has made the test results available for public review. ${ }^{1}$ For benchmarking purposes, CALiPER also includes testing of conventional (i.e., non-LED) lamp types, and luminaires that use conventional light sources. Consumers and manufacturers now have a resource for evaluating and comparing LED and conventional lighting products; more product types are to be tested and benchmarked as CALiPER testing continues.

This benchmark report presents a comparison of T12 and T8 linear fluorescent lamps with commercially available LED linear replacement lamps, in both bare lamp performance and performance in typical lensed and parabolic louver troffer luminaires. CALiPER testing addressed a range of standard lighting measures, including power usage, luminous flux, photometric distribution, source and luminaire efficacy, correlated color temperature (CCT), and the color-rendering index (CRI). Photometric data published by manufacturers for SSL products also were collected and analyzed to compare manufacturer performance claims with measured performance results. ${ }^{2}$

\footnotetext{
${ }^{1}$ Summary reports for DOE CALiPER testing are available at http://www.netl.doe.gov/ssl/comm testing.htm.

${ }^{2}$ Detailed test reports for products tested under the DOE SSL testing program can be requested at http://www.netl.doe.gov/ssl/comm testing_request.htm.
} 


\section{T12 and T8 Fluorescent Lamps and Troffers}

Since their market introduction in the late 1930s, linear fluorescent lamps have become the primary alternative to incandescent sources for indoor general lighting - particularly in office, educational, and health care facility applications. Fluorescent lamps 4-ft long in troffer fixtures are widely used for new construction, replacement lighting, and retrofits.

Until the 1980s, much of the installed base used T12 lamps with magnetic ballasts. However, this older technology has been largely displaced by slimmer T8 lamps with higher-efficiency electronic ballasts. Lamp and ballast manufacturers continue to improve linear fluorescent light output, efficacy, operating life, and color quality. Similarly, luminaire manufacturers have made significant advances in efficiency and optical control of linear fluorescent fixtures.

\section{Lamp Construction and Attributes}

A linear fluorescent lamp is a low-pressure, mercury vapor discharge source consisting of a tubular glass bulb with a sealed base and electrode at each end. The electrodes (also called cathodes) are coated with a material that, when heated upon lamp starting, emits electrons that establish a current (arc) across the lamp. Ultraviolet (UV) energy generated by the mercury arc irradiates the phosphor coating on the inner bulb wall, which in turn converts UV radiation to radiation in the visible spectrum. Linear fluorescent lamps are omnidirectional sources; that is, they emit light in all directions.

Although fluorescent lamps are available in numerous lengths, diameters, and configurations, this report focuses on commonly used 4-ft-long tubular lamps of 12/8-in.-diameter (T12) and 8/8-in. diameter (T8). Fluorescent lamps also are broadly categorized by phosphor type and color appearance. T12 lamps traditionally use a single halophosphor coating, formulated to produce a desired color appearance - for example, cool white $(\mathrm{CCT} \approx 4100 \mathrm{~K})$ or warm white $(\mathrm{CCT} \approx 3000 \mathrm{~K})$. In contrast, $\mathrm{T} 8$ lamps use rare earth phosphors in a triphosphor blend, to combine light corresponding with primary colors (i.e., red, blue, and green) into white light, in a broad range of nominal CCT values. Although more costly, triphosphor lamps offer higher luminous efficacy, better lumen maintenance, and better color rendering than traditional halophosphor lamps.

\section{Lamp Operation}

Fluorescent lamps require a ballast to supply proper starting voltage as well as control the lamp operating current. Older T12 fluorescent systems generally have magnetic ballasts, which use comparatively simple, heavy metallic components to regulate lamp current, and minimal electronic components for adjusting power quality. Magnetic ballasts operate fluorescent lamps at line frequency (i.e., $60 \mathrm{~Hz}$ ), which can result in visible lamp flicker and audible vibration (buzz) from the ballast. 
T8 lamps are designed for electronic ballasts, which use solid-state components, are smaller, lighter, and quieter, and run cooler than magnetic ballasts. Importantly, electronic ballasts operate lamps at much higher frequency $(>20 \mathrm{kHz})$, effectively increasing lamp "on" time and, by extension, increasing light output and efficacy.

Lamp-ballast systems also are characterized by lamp circuit types, which describe the lamp starting method. The method and frequency of lamp starting are important because the emissive coating on lamp cathodes is diminished with each starting cycle, resulting eventually in lamp failure. For general interior lighting, the two most common lamp circuit/ballast types are

- rapid start - The rapid-start ballast provides low voltage to heat the lamp cathodes before applying higher starting voltage, and it continues to provide cathode heating voltage during normal lamp operation. Continued cathode heating is not required for normal lamp operation, so the associated ballast power draw is considered lost. However, preheating the lamp cathodes decreases the required starting voltage and cathode wear, allowing for more starting cycles and/or extending lamp life. Manufacturers also offer programmed rapid-start ballasts, which optimize cathode preheating to extend lamp life-especially in frequent switching cycle applications (e.g., with occupancy sensors).

- instant start - The instant-start ballast provides a high initial voltage to start the lamp without preheating the cathodes. This starting method degrades the lamp cathodes more quickly than do rapid-start systems; however, eliminating the power draw for cathode heating typically makes instantstart systems more energy efficient.

Fluorescent lamp-ballast systems can be "tuned" for light output and energy usage through specification of an appropriate ballast factor (BF), which in simplest terms is the fraction of rated lamp lumens $(\mathrm{lm})$ that a particular lamp-ballast combination will produce. Currently, T8 electronic ballasts are available with $\mathrm{BF}$ values from less than 0.72 to as high as 1.20 . As an example, a lamp rated at $2800 \mathrm{~lm}$ (initial) operated on a ballast with a BF of 0.88 will produce $2464 \mathrm{~lm}$, or $88 \%$ of its rated light outputwith a corresponding reduction in energy usage. If higher light levels are needed, the same lamp can be operated on a ballast with a higher BF and higher system power draw. Fluorescent lamps also can be dimmed - to as low as $1 \%$ of their measured full light output — using dimming electronic ballasts and associated controls.

Fluorescent lamps are sensitive to ambient temperature, which affects the bulb wall temperature and internal operating pressure. Generally, T12 and T8 lamps are designed for maximum light output at an ambient temperature of approximately $25^{\circ} \mathrm{C}\left(77^{\circ} \mathrm{F}\right)$, and manufacturer ratings are based on these conditions. Temperatures below or above the $25^{\circ} \mathrm{C}$ optimum can significantly diminish lamp light output. In most cases, the air temperature near the lamp within a luminaire is greater than $25^{\circ} \mathrm{C}$, resulting in light output and efficacy lower than manufacturer ratings for the lamp ballast system. Less frequently, air currents (drafts) may cool the lamp, diminish its light output, and potentially interfere with proper lamp starting and operation.

\section{Fluorescent Troffer Luminaires}

A fluorescent troffer (a word that combines trough and coffer) is typically an inverted metal trough that houses and serves as a reflector for a fluorescent lamp-ballast system, taking the omnidirectional light from the lamp and reflecting in one hemisphere. Standard dimensions include 1-ft by 4-ft and 2-ft 
by 4-ft fixtures for nominal 4-ft lamps (e.g., T12, T8, and T5 lamps); and 2-ft by 2-ft fixtures for Ushaped fluorescent lamps and biaxial compact fluorescent lamps (CFLs). Frequently, troffers are used in suspended (dropped) acoustic tile ceilings, where their standard dimensions and drop-in design allow for easy installation.

Light is directed out of a troffer by either a lens or parabolic louvers (Figure 2). Lensed fluorescent troffers typically use an acrylic lens to diffuse the light from the lamp(s) and reduce glare. The fixture light output generally has a cosine-shaped distribution, similar to a teardrop (Figure 3). Because the lens acts as a diffuser, the fixture (or array of fixtures) presents a large luminous area that can create veiling reflections on video display terminals (VDTs) (e.g., computer screens) and some paper reading materials. In addition, some lens designs may allow distinct lamp images to be seen through the lens, which users may find objectionable.
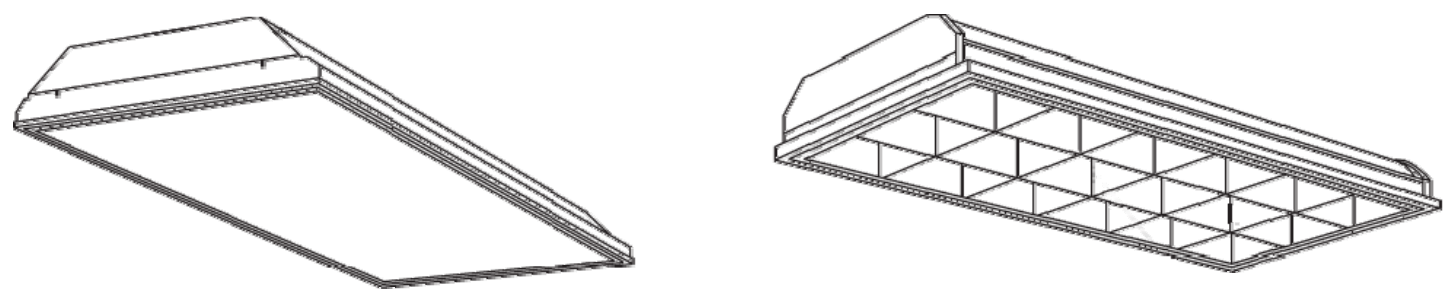

Figure 2. Lensed (left) and Parabolic (right) Troffer Construction

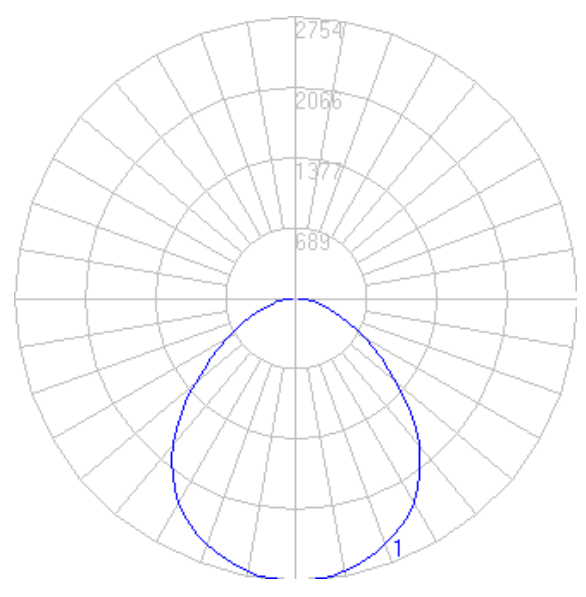

Cosine Distribution - Lensed

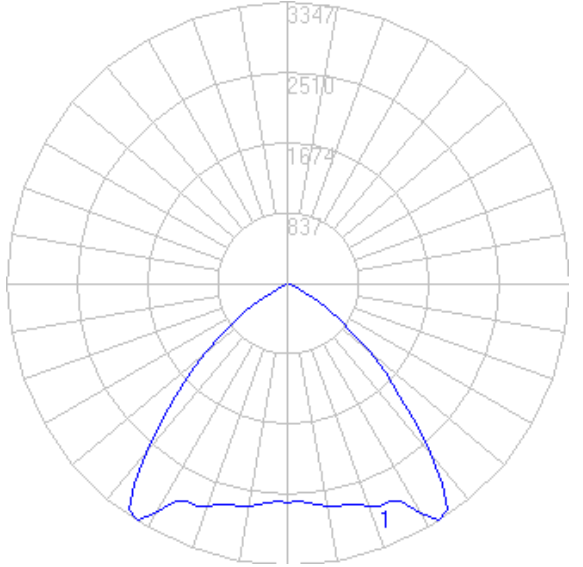

Batwing Distribution - Parabolic

Figure 3. Lensed and Parabolic Louver Troffer Light Distribution

In a parabolic louver troffer, louvers both shape the light distribution and help shield the lamps from direct view, reducing glare. The louvers prevent direct view of the lamp, allowing light to leave the luminaire while reducing the overall luminous surface area, which helps to control veiling reflections in VDT-intensive environments. As suggested by their name, the louvers act as parabolic reflectors, which have the unique feature of gathering light from an omnidirectional source and redirecting it in parallel rays. Parabolic louver fixtures often are described as having a batwing distribution (Figure 3), ideal for providing uniform illumination in general lighting applications. 
Fluorescent troffers are categorized also by their air-handling capability; that is, whether their construction allows air movement through the fixture for heating, ventilation, and air-conditioning purposes. Troffers with no air-handling capability are referred to as static. Based on available data, the vast majority of 2-ft by 4-ft recessed troffers shipped by manufacturers in the United States are static troffers. ${ }^{3}$ Both air-handling and static troffers can affect the thermal environment surrounding the lamp, resulting in temperatures above or below the lamp optimum (e.g., $25^{\circ} \mathrm{C}$ for $\mathrm{T} 12$ and $\mathrm{T} 8$ lamps), which decreases light output and system efficacy.

\section{Performance of T12 and T8 Fluorescent Troffers}

To better understand the performance of existing fluorescent troffers, CALiPER analyzed photometric data for 25 different 2 -ft by 4 -ft two-lamp parabolic louver troffers from five manufacturers. ${ }^{4}$ The luminaires studied included general-service or standard troffers as well as a highly efficient two-lamp replacement for a three-lamp (saving up to 34\% energy) option.

In addition, CALiPER performed benchmark testing of two representative fluorescent troffers as well as bare-lamp testing of their associated linear fluorescent lamps:

- lensed troffer (CALiPER Test ID 08-30) - Equipped with prismatic lens, two F40T12 lamps and electronic ballast.

- parabolic louver troffer (CALiPER Test ID 08-28) - Equipped with 12-cell parabolic louver, two F32T8 lamps, and electronic ballast.

Because linear fluorescent lamps are omnidirectional sources, a portion of their light output is trapped within the troffer. Consequently, an important measure of fluorescent fixture performance is fixture efficiency (also referred to as luminaire efficiency) - that is, the ratio of light emitted by the fixture to the lumen output of the lamp-ballast system alone. Based on surveyed manufacturer data from 25 fixtures, fixture efficiency for parabolic louver troffers ranges between $64 \%$ and $90 \%$, averaging approximately 74\%. The CALiPER-tested parabolic louver troffer (Test ID 08-28) achieved a fixture efficiency of $60 \%$, lower than its rated efficiency of $76 \%$.

CALiPER did not review manufacturer data for lensed troffers, which have fewer optical components (e.g., baffles, louvers) and would be expected to have higher fixture efficiencies than parabolic louver troffers, on average. The CALiPER-tested lensed troffer (Test ID 08-30) had a fixture efficiency of $72 \%$, $12 \%$ higher than the tested parabolic louver troffer.

The 2-ft by 4-ft troffers appear to be, on average, more efficient than fluorescent troffer fixtures with other formats, based on comparison to data from a limited number of troffers of other formats. Manufacturer data from two parabolic louver troffers that are equipped with three lamps (2-ft by 4-ft, three-lamp) show fixture efficiencies of $60 \%$ to $62 \%$. Manufacturer data from a narrower two-lamp

\footnotetext{
${ }^{3}$ Approximately $87 \%$ of 2-ft by 4 -ft recessed troffers shipped in 2001 were static troffers (from U.S. Census Bureau Current Industrial Reports, “Electric Lighting Fixtures: 2001,” issued January 2003).

${ }^{4}$ Surveyed manufacturers included Columbia Lighting, Lightolier, Prudential Lighting, Lithonia Lighting, and Legion Lighting Company, Inc.
} 
parabolic louver troffer (1-ft by 4-ft, two-lamp) show a fixture efficiency of 59\%. For a $2-\mathrm{ft}$ by $2-\mathrm{ft}$ parabolic louver troffer equipped with two $17-\mathrm{W}$ T8 lamps, the fixture efficiency is only $49 \%$.

Fixture efficiency directly affects luminaire efficacy, which represents the luminaire light output divided by luminaire input power, expressed in lumens per watt $(1 \mathrm{~m} / \mathrm{W})$. Accounting for ballast factor and the input power of the combined lamp-ballast system, luminaire efficacy can be calculated as follows:

$$
\text { Number of lamps/luminaire } \times \text { rated lamp light output }(\mathrm{lm}) \times \mathrm{BF} \times \text { fixture efficiency }
$$

Luminaire input power $(\mathrm{W})$

Table 1 presents a summary of manufacturer data and CALiPER testing results for two-lamp fluorescent parabolic louver troffers.

Table 1. Manufacturer and CALiPER Benchmarks for Two-Lamp Fluorescent Parabolic Louver Troffers

\begin{tabular}{lccc}
\hline & \multicolumn{3}{c}{ Performance of Two-Lamp Fluorescent Parabolic Louver Troffers } \\
\cline { 2 - 4 } & $\begin{array}{c}\text { Average from } \\
\text { Surveyed } \\
\text { Manufacturer Ratings }\end{array}$ & $\begin{array}{c}\text { Range Observed in } \\
\text { Manufacturer Ratings }\end{array}$ & $\begin{array}{c}\text { CALiPER Benchmark } \\
\text { Test Results } \\
\text { (Test ID 08-28) }\end{array}$ \\
\hline Total lamp lumens & 5900 & $5200-6400$ & 6125 \\
Luminaire input power $(\mathrm{W})$ & 68 & $55-88$ & 58 \\
Fixture efficiency $(\%)$ & 74 & $64-90$ & 60 \\
Luminaire efficacy $(\mathrm{lm} / \mathrm{W})$ & 66 & $50-96$ & 63 \\
\hline
\end{tabular}

In addition to key performance metrics such as output, efficacy, and efficiency, the effectiveness of light distribution is a key metric for troffers. Tables 2 and 3 summarize the average luminance at various angles and the average percentage of zonal lumens for the 25 parabolic louver troffers using linear fluorescent sources. Results from the CALiPER benchmark test (Test ID 08-28) of a parabolic louver troffer equipped with two fluorescent T8 lamps fall within these ranges.

Table 2. Average Luminance Data for Parabolic Troffers

\begin{tabular}{|c|c|c|c|c|c|c|c|c|c|}
\hline \multirow{2}{*}{$\begin{array}{l}\text { Vertical } \\
\text { Angle in } \\
\text { Degrees }\end{array}$} & \multicolumn{3}{|c|}{$\begin{array}{l}\text { Average }\left(\mathrm{cd} / \mathrm{m}^{2}\right) \\
0 \text {-Degree (along) }\end{array}$} & \multicolumn{3}{|c|}{$\begin{array}{c}\text { Average }\left(\mathrm{cd} / \mathrm{m}^{2}\right) \\
\text { 45-Degree }\end{array}$} & \multicolumn{3}{|c|}{$\begin{array}{c}\left.\text { Average (cd/ } / \mathrm{m}^{2}\right) \\
90 \text {-Degree (across) }\end{array}$} \\
\hline & Average & Min & Max & Average & Min & Max & Average & Min & Max \\
\hline 45 & 2334 & 1851 & 2772 & 3151 & 2425 & 3987 & 3940 & 2653 & 4938 \\
\hline 55 & 1982 & 207 & 2627 & 3066 & 833 & 4139 & 2787 & 124 & 4100 \\
\hline 65 & 932 & 0 & 1996 & 1145 & 0 & 2692 & 1003 & 0 & 2497 \\
\hline 75 & 172 & 0 & 1455 & 203 & 0 & 1380 & 213 & 0 & 1155 \\
\hline 85 & 86 & 0 & 1038 & 96 & 0 & 927 & 84 & 0 & 612 \\
\hline
\end{tabular}

Note: Photometric software analyzes the luminance and provides the mean luminance per horizontal and vertical value. These mean values were then averaged to determine the average across the luminaires analyzed. 
Table 3. Average Zonal Lumen Summary for Lensed and Parabolic Troffers

\begin{tabular}{ccccccc}
\hline & \multicolumn{3}{c}{ \% Lamp } & & \% Fixture \\
\cline { 2 - 7 } Zone & Average & Minimum & Maximum & Average & Minimum & Maximum \\
\hline $0-30$ & 21 & 16 & 24 & 29 & 20 & 34 \\
$0-40$ & 37 & 29 & 46 & 49 & 49 & 66 \\
$0-60$ & 68 & 59 & 81 & 92 & 90 & 100 \\
$0-90$ & 74 & 64 & 90 & 100 & 98 & 100 \\
$90-180$ & 0 & 0 & 0 & 0 & 0 & 0 \\
$0-180$ & 75 & 64 & 90 & 100 & 98 & 100 \\
\hline
\end{tabular}

The luminance data in Table 2 typically are listed in a photometric report and show the fixture luminance at various angles (both horizontal and vertical). The luminance data allow for comparison of luminaires, taking into account louver specularity and cutoff characteristics and potential for glare. The zonal lumen distributions (Table 3) ultimately affect the luminaire spacing needed to achieve desired light levels for a given application. Luminaire spacing determines the number of luminaires needed and thus can influence the total energy use of a lighting system.

\section{LED Replacements for T12 and T8 Fluorescent Lamps in Troffer Luminaires}

Light-emitting diode replacements for linear fluorescent lamps are basically a rectilinear LED array, mounted in a tubular format, typically with bi-pin bases that are compatible with standard fluorescent lampholders. Unlike linear fluorescent lamps, which emit light in an omnidirectional pattern, LED replacements are directional sources intended to emit light more directly out of the fixture (e.g., downward in the case of a troffer). Manufacturer claims for these products generally focus on energy savings, long life, reduced maintenance, and mercury-free composition. Manufacturer photometric data - if provided - range from lumen outputs to illuminance values to claims of general equivalency with fluorescent lamps (see "Untangling Claims..." section below).

All the 4-ft LED replacement lamps tested by CALiPER featured a linear array of phosphorconverted white LEDs (ranging from 36 to 300 LEDs per lamp), with integrated driver and heat sinking. Figure 4 provides images of the LED linear replacement lamps. As illustrated in these images, some of these replacement lamps have clear tubular plastic covers and some have lenses that serve as diffusers. All except one of the LED linear replacement lamps tested by CALiPER to date have the size, shape, and bi-pin connector similar to typical fluorescent T8 lamps. One LED replacement lamp currently undergoing testing is a long, flat strip requiring installation of a clip-based mounting system to mount in troffers. 


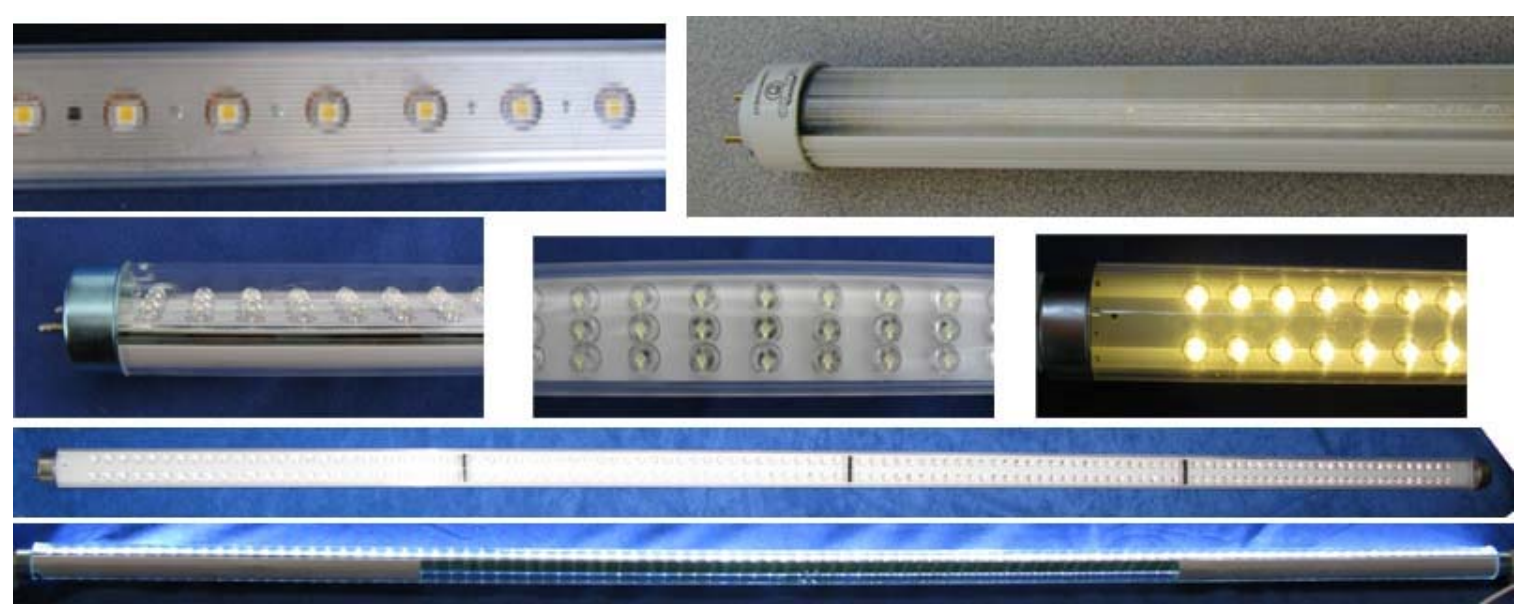

Figure 4. Typical LED Linear Replacement Lamps

With the exception of one ballast-compatible product (CALiPER Test ID 07-56), the tested LED replacements would require bypassing the existing fluorescent ballast and wiring the LED lamps to a line voltage (e.g., $120-\mathrm{V}$ or $277-\mathrm{V}$ ) circuit. Despite the relative ease of installing properly sized LED replacement lamps in fluorescent lampholders, the additional labor for electrical connections could entail significant expense, depending on the scale of a retrofit project. The added labor for installing LED replacement lamps with a clip-based mounting system would also contribute to retrofit project costs.

Although marketed as a general fluorescent replacement for interior applications, the LED replacement lamps tested by CALiPER were generally available with only a cool (CCT $5000 \mathrm{~K}-7000 \mathrm{~K}$ ) color appearance. ${ }^{5}$ In comparison, many commercial and institutional fluorescent applications employ a neutral or cool white appearance (e.g., CCT $3500 \mathrm{~K}-4100 \mathrm{~K}$ ). Fluorescent lamps are often specified to integrate with other light sources (e.g., halogen), and higher CCT LED replacements may create an unacceptable color contrast in these applications.

LEDs are inherently directional light sources, which suggests that LED linear replacement lamps would deliver a higher percentage of their total lamp lumens out of a troffer than an omnidirectional fluorescent source. Figure 5 illustrates how the directionality of a light source may impact the fixture efficiency. The lamp in scenario A is a typical omnidirectional lamp (e.g., T12 or T8 fluorescent lamp). Absorption of light in the luminaire housing and louvers typically limits fixture efficiency to between $60 \%$ and $70 \%$. Scenarios B and C show the direction of light emission from two possible drop-in LED linear replacement lamps, with the LED array mounted in the center of the replacement lamp. Fixture efficiency is potentially higher in these configurations because more lamp lumens are directed out of the fixture than are absorbed in fixture components. Note, however, that the troffer is designed around an omnidirectional source and that omitting lamp output at higher angles could affect the overall light distribution of the fixture.

\footnotetext{
${ }^{5}$ One LED replacement product (CALiPER Test ID 07-56) was available with CCT values from $2700 \mathrm{~K}$ to $6500 \mathrm{~K}$. The 3500-K version was CALiPER-tested.
} 


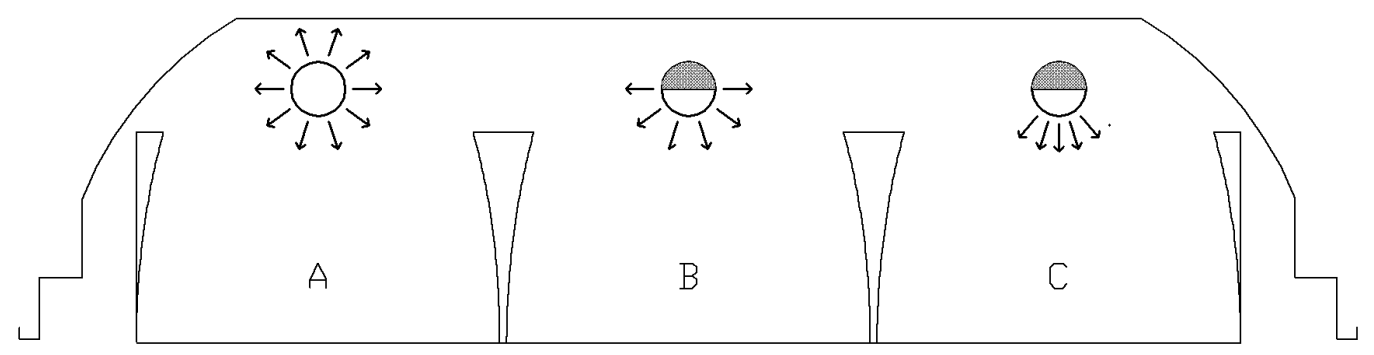

Figure 5. Directionality of Linear Fluorescent (A) and LED Replacement Lamps (B and C) in Relation to Typical Parabolic Louver Troffer Construction

Manufacturer literature for some LED linear replacement products argues or implies that — by virtue of their directionality - the LED products achieve equal or greater illumination levels with far less overall lumens compared to fluorescent products. Similarly, manufacturer literature for LED replacements also typically implies that they provide energy savings as compared to similar fluorescent products. One objective of CALiPER testing was to determine if these claims are valid or if they are inaccurate and misleading.

\section{Performance of LED Replacements for Linear Fluorescent Lamps}

To date, CALiPER has tested four LED products intended as replacements for linear fluorescent lamps. Testing included bare lamp performance as well as in situ performance in typical two-lamp lensed and parabolic louver troffers. For benchmarking purposes, CALiPER also tested typical T12 and T8 fluorescent lamps for bare lamp and in situ performance, in the same two-lamp lensed (T12) and parabolic (T8) troffers. Table 4 summarizes CALiPER test results for bare lamp testing, with LED product performance discussed below. Values for CCT and power factor that are clearly outside industry norms are in red italics.

Table 4. Summary of CALiPER Bare Lamp Testing for 4-ft Linear Fluorescent Lamps and LED Replacements

\begin{tabular}{|c|c|c|c|c|c|c|c|c|}
\hline & $\begin{array}{c}\text { DOE } \\
\text { CALiPER Test ID }\end{array}$ & $\begin{array}{l}\text { Total } \\
\text { Power } \\
\text { (W) }\end{array}$ & $\begin{array}{l}\text { Output } \\
\text { (initial } \\
1 \mathrm{~m} \text { ) }\end{array}$ & $\begin{array}{l}\text { Efficacy } \\
(\mathrm{lm} / \mathrm{W})\end{array}$ & $\begin{array}{l}\mathrm{CCT} \\
(\mathrm{K})\end{array}$ & CRI & $\begin{array}{c}\operatorname{Max} \\
D_{u v}\end{array}$ & $\begin{array}{l}\text { Power } \\
\text { Factor }\end{array}$ \\
\hline 4-ft replacement lamp, LED & $07-56$ & 25 & 1058 & 42 & 3494 & 75 & -0.001 & 0.86 \\
\hline 4-ft replacement lamp, LED & $08-17$ & 20 & 849 & 43 & 12583 & 72 & 0.007 & 0.51 \\
\hline 4-ft replacement lamp, LED & 08-19 & 18 & 345 & 19 & 2971 & 72 & 0.004 & 0.72 \\
\hline 4-ft replacement lamp, LED & $08-37$ & 19 & 1016 & 52 & 7739 & 76 & 0.005 & 0.53 \\
\hline $\begin{array}{l}\text { F32T8, 4-ft linear } \\
\text { fluorescent }\end{array}$ & $08-28$ & 32 & 3081 & 96 & 3932 & 81 & 0.003 & 0.99 \\
\hline $\begin{array}{l}\text { F40T12, 4-ft linear } \\
\text { fluorescent }\end{array}$ & $08-30$ & 39 & 3101 & 80 & 2884 & 84 & 0.001 & 0.89 \\
\hline
\end{tabular}




\section{Light Output}

As shown in Figure 6, CALiPER-measured light outputs for currently available LED linear replacement lamps fall far short of measured light output for benchmarked T12 and T8 fluorescent lamps. In these samples, the best performing bare lamp using LEDs produces only one-third the light output of a typical 4-ft fluorescent lamp.

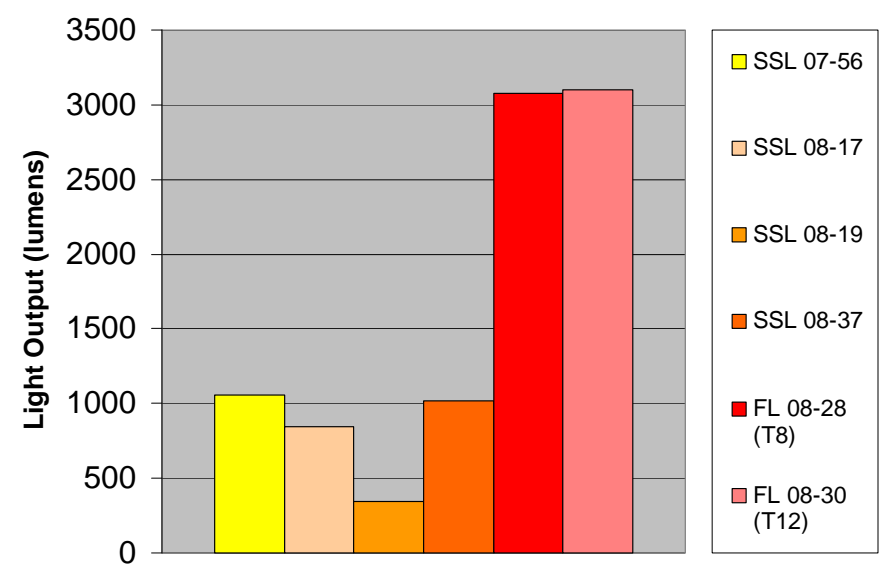

Figure 6. Measured Light Output of 4-ft LED Linear Replacement Lamps Compared to 4-ft Linear Fluorescent Lamps

Figure 7 presents a comparison of measured light output and corresponding manufacturer claims for tested LED and fluorescent lamps. One LED product claimed significantly higher light output than was measured in CALiPER testing.

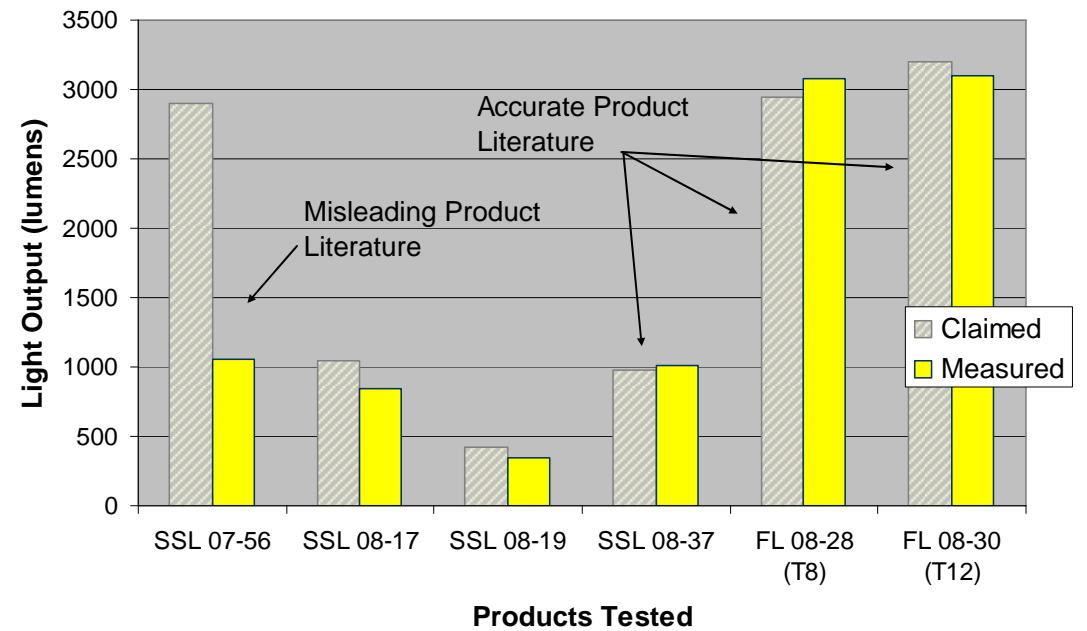

Figure 7. Measured Light Output of 4-ft Linear Fluorescent Lamps and LED Replacements Compared to Manufacturers' Reported Values ${ }^{6}$

\footnotetext{
${ }^{6}$ For CALiPER Test ID 07-56, manufacturer data did not provide light output for the $3500-\mathrm{K}$ version, so the claimed light output for the 4100-K version $(2900 \mathrm{~lm}$ ) is used for comparison. For Test ID 08-17, the 


\section{Lamp Efficacy}

Lamp efficacy is the light output of a lamp divided by its power usage, expressed in lumens per watt. As illustrated in Figure 8, claimed efficacies for LED linear replacement lamps rival their fluorescent counterparts. However, as predicted by their relatively low light outputs, measured efficacies for the LED products were considerably lower than for the fluorescent benchmarks.

Both linear fluorescent products were found to have accurate product information regarding efficacy. All four LED linear replacement lamps were found to have inaccurate or misleading manufacturer information regarding their efficacy.

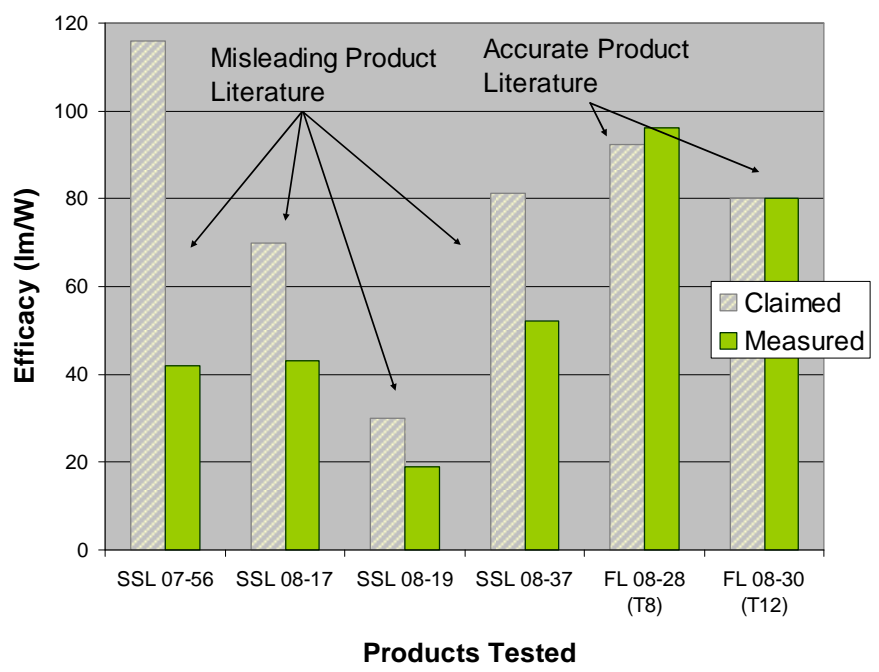

Figure 8. Measured Efficacy of 4-ft Linear Fluorescent Lamps and LED Replacements Compared to Manufacturers' Reported Values ${ }^{7}$

\section{Lamp Directionality and Fixture Efficiency}

Product literature often implies that, given their inherent directionality, LED replacement lamps can achieve equal or greater luminaire light output (and illumination levels) with far less total lumens compared to fluorescent lamps. CALiPER in situ tests of linear replacement lamps in typical troffers allow us to examine fixture efficiency, luminaire efficacy, and light distribution from troffers equipped with these LED linear replacement lamps as compared to linear fluorescent lamps.

CALiPER in situ test results for two-lamp lensed and parabolic louver troffers confirm thatindependent of their light output and efficacy_LED linear replacement lamps achieve higher fixture

manufacturer's claimed light output was unclear (presented as a range of 1050-3000 lm), so the lower value (1050 $\mathrm{lm})$ is presented for comparison.

${ }^{7}$ For CALiPER Test ID 07-56, manufacturer data did not provide light output for 3500-K version, so the claimed light output for the $4100-\mathrm{K}$ version $(2900 \mathrm{~lm}$ ) was used to calculate claimed lamp efficacy. For Test ID 08-17, the manufacturer's claimed light output was unclear (presented as a range of 1050-3000 lm), so the lower value $(1050 \mathrm{~lm})$ was used to calculate claimed lamp efficacy. 
efficiencies than T12 and T8 fluorescent lamps in the same fixtures (Table 5). In the lensed troffer, fixture efficiency when operated with LED replacements lamps is $11 \%$ to $17 \%$ higher than when operated with linear fluorescent lamps. In the parabolic louver troffer, fixture efficiency with LED replacement lamps is $14 \%$ to $26 \%$ higher than with linear fluorescent lamps. However, even with this increased fixture efficiency, the best-performing LED replacements could not deliver even one-half the light output of the benchmarked fluorescent sources when operated in situ in troffers.

Table 5. Summary of CALiPER Testing for 4-ft Linear Fluorescent Lamps and LED Replacements in Lensed and Parabolic Louver Troffers

\begin{tabular}{|c|c|c|c|c|c|}
\hline & $\begin{array}{c}\text { DOE } \\
\text { CALiPER } \\
\text { Test ID }\end{array}$ & $\begin{array}{l}\text { Total } \\
\text { Power } \\
\text { (W) }\end{array}$ & $\begin{array}{c}\text { Output } \\
\text { (initial lm) }\end{array}$ & $\begin{array}{l}\text { Efficacy } \\
(\operatorname{lm} / \mathrm{W})\end{array}$ & $\begin{array}{l}\text { Fixture } \\
\text { Efficiency } \\
\text { (in situ) }\end{array}$ \\
\hline \multicolumn{6}{|c|}{ 4-ft Linear Replacement Lamps in Lensed T12 Troffer } \\
\hline 2 x $4 \mathrm{ft}$ Replacement lamp, LED & $07-56$ & 80 & 2125 & 27 & (a) \\
\hline 2 x $4 \mathrm{ft}$ Replacement lamp, LED & $08-17$ & 40 & 1451 & 36 & $85 \%$ \\
\hline 2 x $4 \mathrm{ft}$ Replacement lamp, LED & $08-19$ & 36 & 613 & 17 & $89 \%$ \\
\hline 2 x 4 ft Replacement lamp, LED & $08-37$ & 40 & 1693 & 43 & $83 \%$ \\
\hline $2 \times 4 \mathrm{ft} \mathrm{F} 40 \mathrm{~T} 12$, linear fluorescent & $08-30$ & 88 & 4453 & 51 & $72 \%$ \\
\hline \multicolumn{6}{|c|}{ 4-ft Linear Replacement Lamps in Parabolic T8 Troffer } \\
\hline $2 \times 4 \mathrm{ft}$ Replacement lamp, LED & $07-56$ & 47 & 1566 & 33 & $74 \%$ \\
\hline 2 x $4 \mathrm{ft}$ Replacement lamp, LED & $08-17$ & 40 & 1399 & 35 & $82 \%$ \\
\hline $2 \times 4 \mathrm{ft}$ Replacement lamp, LED & $08-19$ & 36 & 597 & 17 & $86 \%$ \\
\hline $2 \times 4 \mathrm{ft}$ Replacement lamp, LED & $08-37$ & 39 & 1711 & 43 & $84 \%$ \\
\hline $2 \times 4 \mathrm{ft}$ F32T8, linear fluorescent & $08-28$ & 58 & 3675 & 63 & $60 \%$ \\
\hline
\end{tabular}

(a) Calculated fixture efficiency based on (in situ output)/(bare lamp output $\mathrm{A}+$ bare lamp output B). Bare lamp testing on 07-56 was conducted with a reference ballast corresponding to the lamp's rated power at $25 \mathrm{~W}$, so fixture efficiency was not calculated for this product in the T12 troffer due to significantly different operating power level. Sample 07-56 uses the troffer ballast while the other three LED linear replacement lamps bypass the troffer ballast and use their own power supplies.

\section{Luminaire Efficacy}

CALiPER testing indicates that, despite achieving higher luminaire efficiencies, LED linear replacements fall far short of linear fluorescent lamps in lamp light output and lamp efficacy. Consequently, T12 and T8 fluorescent lamp-ballast systems - with higher power usage and lower fixture efficiencies - are able to leverage their sheer performance in lamp output and efficacy to achieve higher luminaire efficacies than LED replacement products. Figure 9 presents in situ luminaire efficacy as a function of light output for the CALiPER-tested linear fluorescent lamps and LED replacement products. Clearly, the troffers equipped with LED replacement lamps do not achieve even half of the light output of the same troffers equipped with linear fluorescent lamps. Consequently, the best-performing LED replacement lamp was not able to match even the modest luminaire efficacy of the lensed troffer with T12 fluorescent lamps. 


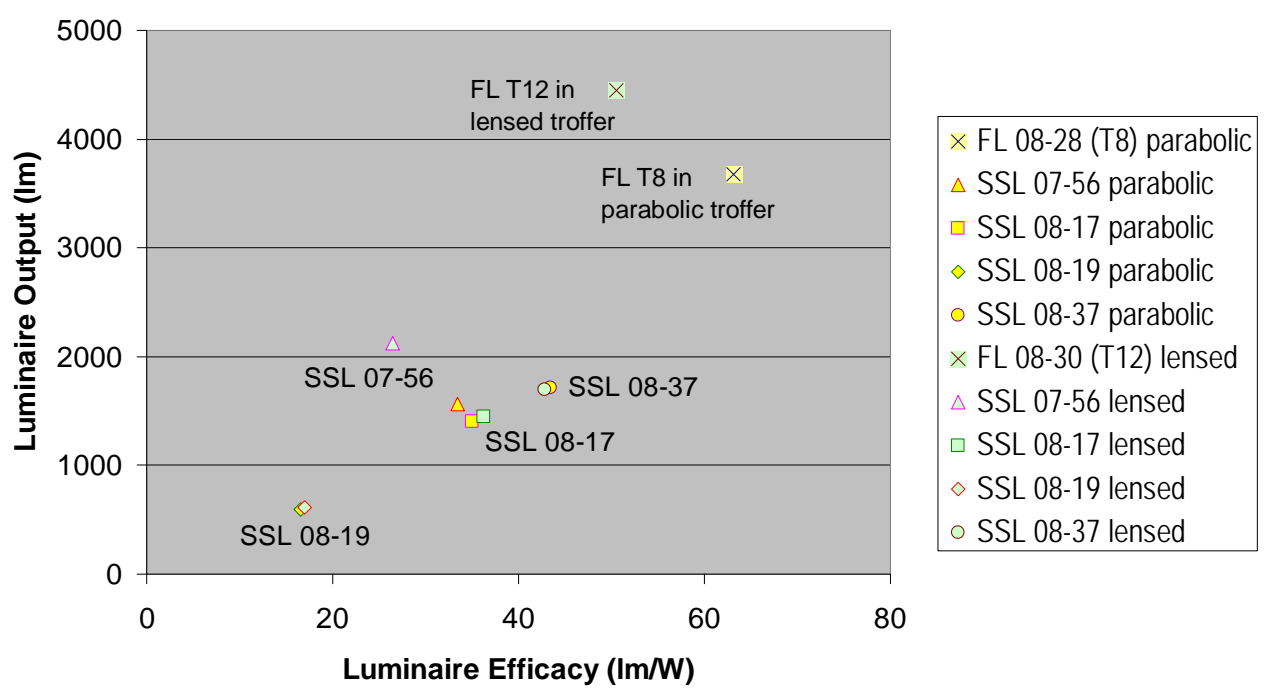

Figure 9. Luminaire Output Versus Efficacy for 4-ft Linear Fluorescent Lamps and LED Replacements in Lensed and Parabolic Louver Troffers

\section{Luminaire Light Distribution and Resulting Illumination}

Both lensed and parabolic louver troffers are designed to spread their light output, to varying degrees, to enhance illumination uniformity. Linear fluorescent lamps emit light at higher angles than LED replacements, which not only directly contributes to a broader light distribution (e.g., with lensed troffers) but also interacts with troffer components designed to redirect light for illumination uniformity (e.g., baffles and louvers in parabolic louver troffers). In contrast, LED linear replacement lamps direct more of their light output downward from the troffer with less spread.

Figures 10 and 11 present measured intensity distributions and calculated zonal lumen density percentages for the troffers tested by CALiPER as well as provide a graphical and numerical representation of troffer performance with fluorescent lamps and representative LED linear replacements. As illustrated in Figure 10, the LED replacement lamps produce a similar (but narrower) distribution to T12 fluorescent lamps in the lensed troffer-with significantly lower luminous intensity. In a parabolic louver troffer (Figure 11), LED linear replacement lamps fail to produce the luminous intensity and desired batwing distribution provided by the benchmark T8 fluorescent lamps.

Luminaire manufacturers provide zonal lumen density summaries as another indicator of fixture light distribution - that is, the quantity of light emitted in annular zones defined by vertical angles. The zonal lumen percentages presented in Figures 10 and 11 illustrate relative light output in $10^{\circ}$ vertical increments and are not indicators of absolute luminous intensity or flux at any particular angle. For the lensed troffer (Figure 10), it is apparent that the LED replacement lamps (a directional source) produce proportionately more light output below the fixture (i.e., below $40^{\circ}$ vertical), resulting in a narrower distribution. In contrast, the T12 fluorescent lamps (an omnidirectional source) produce a greater percentage of light output at higher angles (i.e., above $40^{\circ}$ vertical), yielding a broader distribution. The troffer lens serves largely to reduce lamp imaging and glare; consequently, the fixture light distribution is a function primarily of lamp type. 


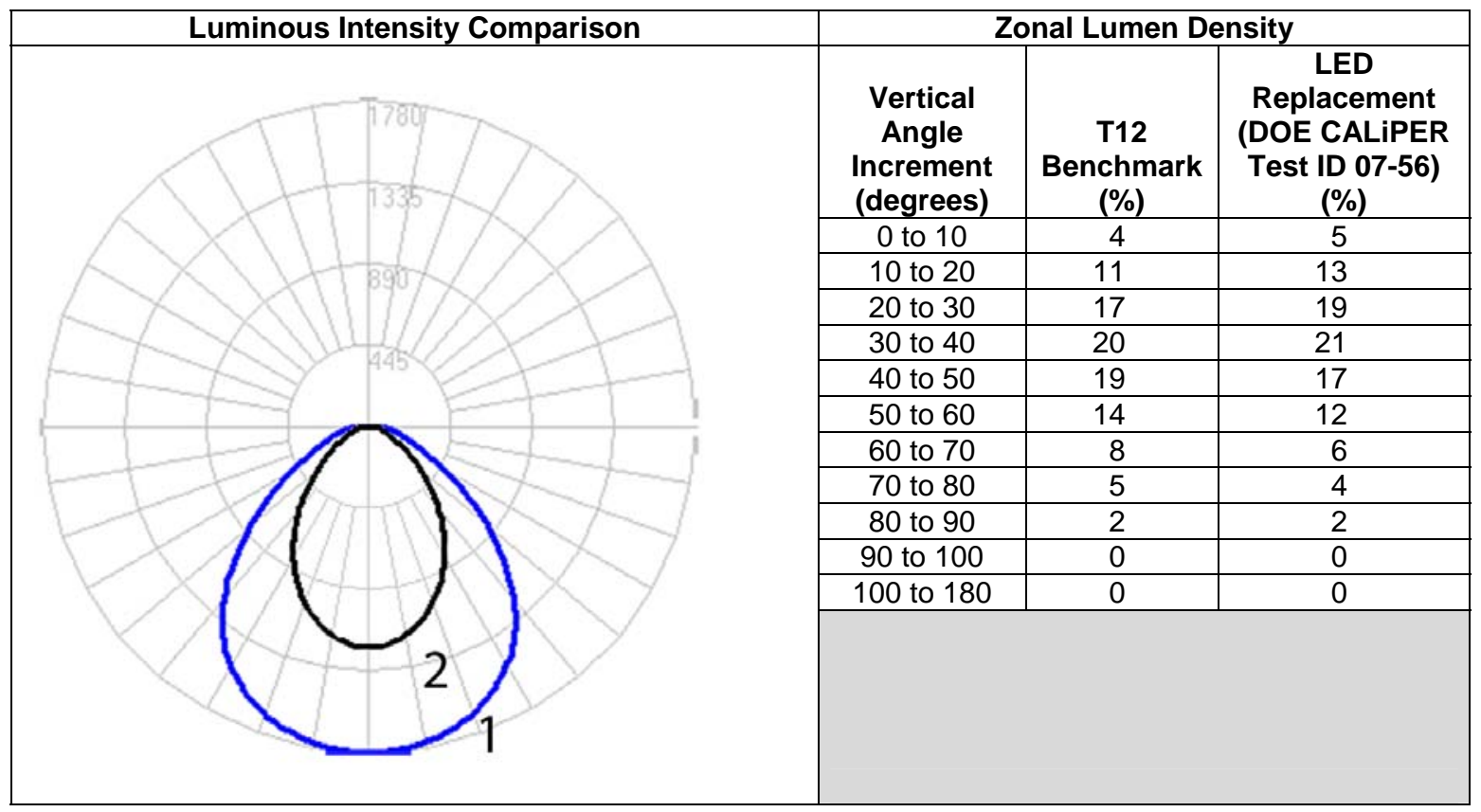

Figure 10. Measured Luminous Intensity Distributions and Calculated Zonal Lumen Density Percentages for Lensed Troffer with Two 4-ft T12 Fluorescent Lamps (Curve 1) and LED Replacements (Curve 2)

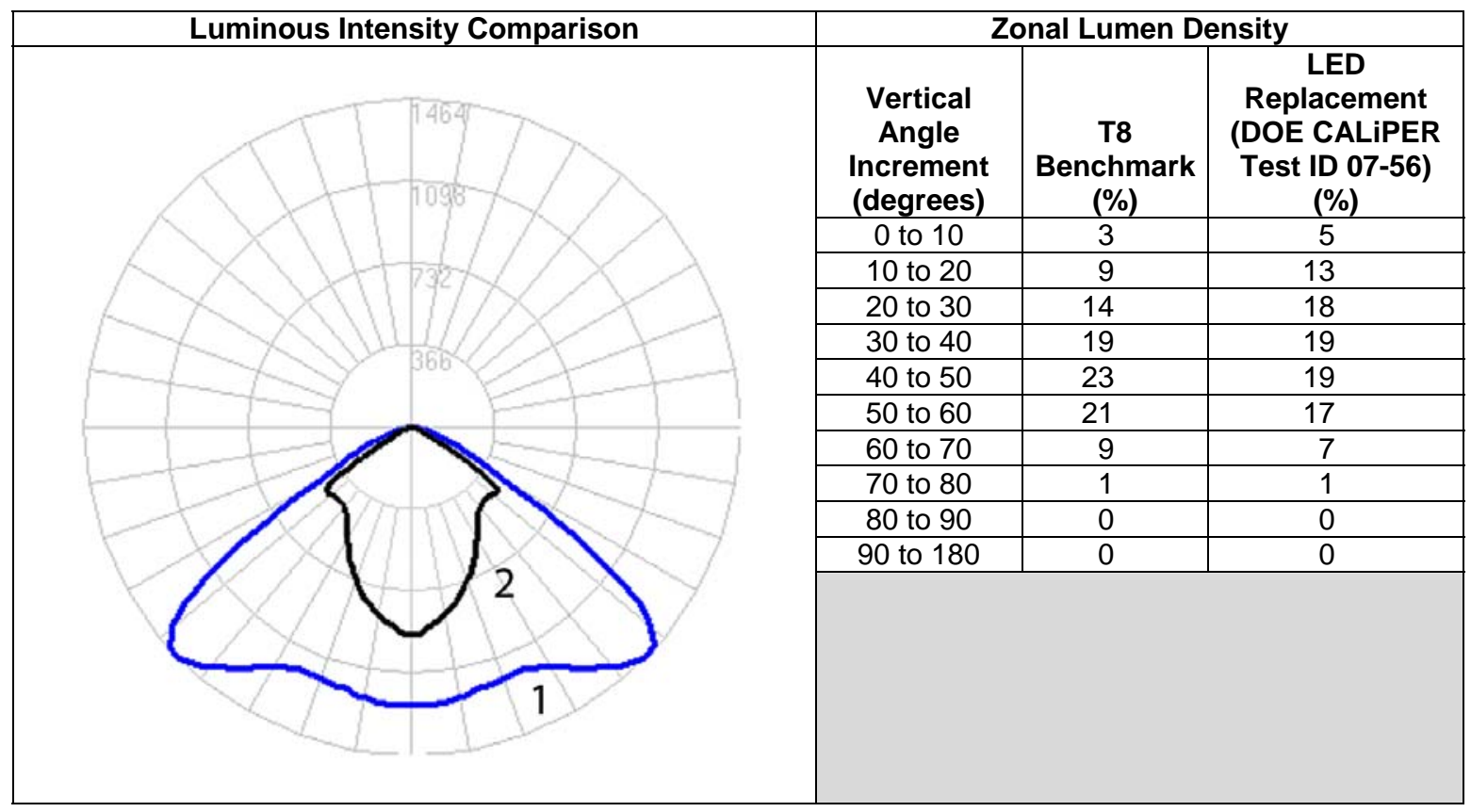

Figure 11. Measured Luminous Intensity Distributions and Calculated Zonal Lumen Density Percentages for Parabolic Louver Troffer with Two 4-ft T8 Fluorescent Lamps (Curve 1) and LED Replacements (Curve 2) 
The louvers in a parabolic louver troffer - in addition to mitigating glare - are designed to gather and redirect light from linear fluorescent sources, producing a characteristic batwing distribution (Figure 11). This is evidenced further by proportionally higher light output in the $40^{\circ}$ to $60^{\circ}$ zone for the benchmark T8 fluorescent configuration. With more directional output, the LED replacement lamps interact less with the louver optics and do not generate a fixture light distribution as wide as the linear fluorescents.

The Appendix provides luminous intensity distributions and zonal lumen summaries for the lensed and parabolic louver troffers with benchmark fluorescent sources and all LED replacement lamps tested by CALiPER. Fixture luminance data (calculated based on fixture intensity distributions) also are presented and provide another illustration of the narrower distribution in troffers for LED products.

The practical effect of a narrower distribution from LED linear replacement lamps is that retrofitted troffers will not provide the same light distribution as when equipped with fluorescent lamps. For a given luminous intensity, illuminance diminishes with distance from the light source; therefore, greater luminous intensity is required at higher angles than directly below the fixture to produce uniform light levels between fixtures. The batwing distribution in Figure 11 (T8 case) illustrates this approach.

To this end, luminaire manufacturers publish recommended spacing criteria, which are mounting height multipliers used to determine the lateral distance between fixtures for uniform lighting. Table 6 presents the recommended spacing criteria for the benchmarked fluorescent troffers; the calculated spacing criteria values required to achieve equal illuminance uniformity using LED replacement lamps (based on CALiPER testing data) also are listed.

Table 6. Spacing Criteria: Fluorescent Versus LED Replacement Lamps

\begin{tabular}{lcccc}
\hline \multicolumn{4}{c}{ Lensed Troffer Spacing Criterion } \\
\hline & T12 Fluorescent & \multicolumn{2}{c}{ LED Linear Replacement Lamps } \\
\cline { 2 - 5 } & Benchmark & Average & Minimum & Maximum \\
\hline $0-180^{\circ}$ (along) & 1.24 & 1.13 & 1.02 & 1.18 \\
$90-270^{\circ}$ (across) & 1.38 & 1.16 & 0.98 & 1.26 \\
Diagonal & 1.36 & 1.23 & 1.06 & 1.30 \\
\hline
\end{tabular}

Parabolic Louver Troffer Spacing Criterion

\begin{tabular}{lcccc}
\hline & T8 Fluorescent & \multicolumn{2}{c}{ LED Linear Replacement Lamps } \\
\cline { 3 - 5 } & Benchmark & Average & Minimum & Maximum \\
\hline $0-180^{\circ}$ (along) & 1.24 & 1.13 & 1.02 & 1.18 \\
$90-270^{\circ}$ (across) & 1.70 & 1.16 & 0.98 & 1.26 \\
Diagonal & 1.62 & 1.23 & 1.06 & 1.30 \\
\hline
\end{tabular}

Spacing criterion is a multiplier. Multiply the net mounting height by the spacing criterion value; the result represents the maximum (center-to-center) distance at which the luminaires may be spaced.

For both lensed and parabolic louver troffers, the spacing criteria values with LED replacement lamps are lower than for the fluorescent benchmark -indicating that more fixtures (with closer spacing) would be required to achieve equally uniform illumination. Additional fixtures would result in increased cost and reduced energy savings. Alternatively, a one-for-one retrofit would likely produce unacceptable decreases in illumination levels and uniformity. 


\section{Color Characteristics}

The color properties of light sources are described by two commonly used measures: CCT and CRI. Linear fluorescent lamps are available in a broad range of color appearances, ranging from warm (CCT $\leq$ $3000 \mathrm{~K}$ ) to cool (CCT $\geq 4100 \mathrm{~K}$ ), with neutral-to-cool color appearance (i.e., CCT $3500 \mathrm{~K}-4100 \mathrm{~K}$ ) specified in many interior applications. As illustrated in Figure 12, the CCT values for most of the CALiPER-tested LED linear replacement lamps were considerably higher than the fluorescent benchmarks; two of the four LED products exceeded industry norms for CCT.
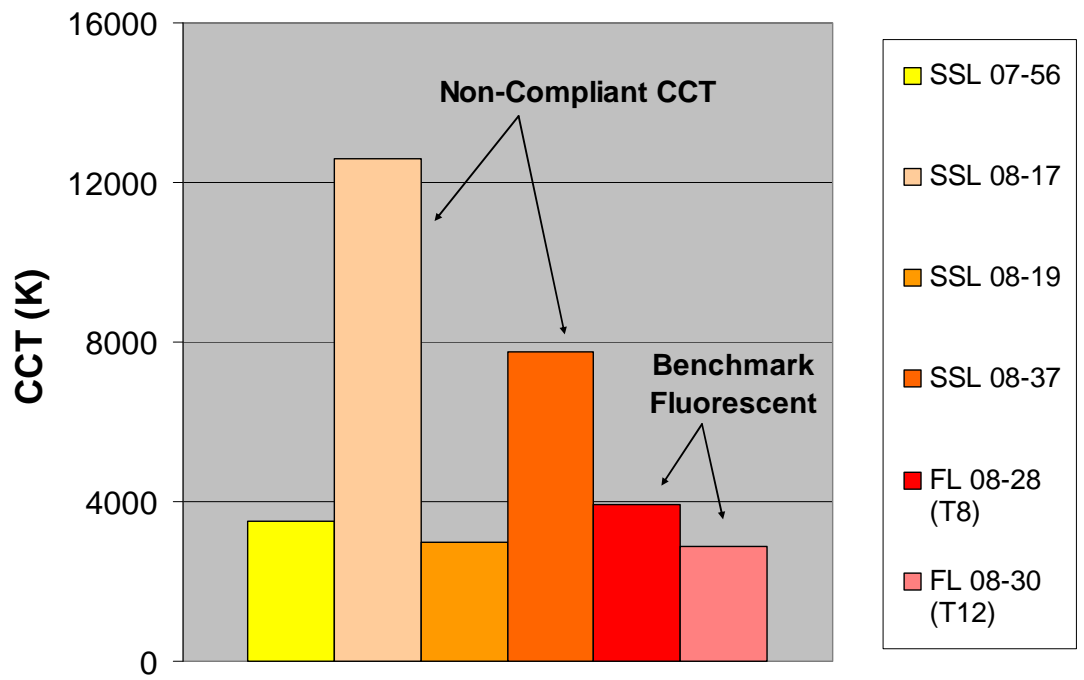

Figure 12. Comparison of Measured CCT Values for Linear Fluorescent Lamps and LED Replacements

Measured CRI values (Table 2) for LED linear replacement lamps were comparable to those for fluorescent benchmarks. However, given the known problems with applying CRI to white light LED products, users should evaluate LED replacement lamps visually to gauge their color quality for a given application. $^{8}$

American National Standards Institute (ANSI) Standard C78.377-2008 establishes chromaticity specifications for white light LED products and uses the $u^{\prime}, v^{\prime}$ diagram (International Commission on Illumination 1976) to illustrate CCT boundaries that fall along a solid curve called the Planckian locus (Figure 13). To meet ANSI specifications, measured chromaticity coordinates for a LED product must plot not only within established CCT boundaries but also within prescribed distances of the Planckian locus (i.e., $\mathrm{D}_{\mathrm{uv}}$ chromaticity targets and tolerances). ${ }^{9}$ As illustrated in Figure 10, the chromaticity coordinates of two white LED products tested fall far from the Planckian locus and do not meet CCT definitions. However, the tested LED products with compliant CCT values also met applicable $\mathrm{D}_{\mathrm{uv}}$ tolerances.

\footnotetext{
${ }^{8}$ See the fact sheet, "LED Measurement Series: Color Rendering Index and LEDs," for more information about LED performance on CRI index tests and recommendations for evaluating color characteristics of LEDs.

${ }^{9}$ For the measured chromaticity coordinates of a source (as plotted on the CIE 1976 (u', v') diagram), the target $D_{u v}$ is the maximum allowable distance from the Planckian (blackbody) locus. This distance is specified for each nominal CCT defined in ANSI C78.377-2008 and relates to the relative whiteness of a light source appearance.
} 


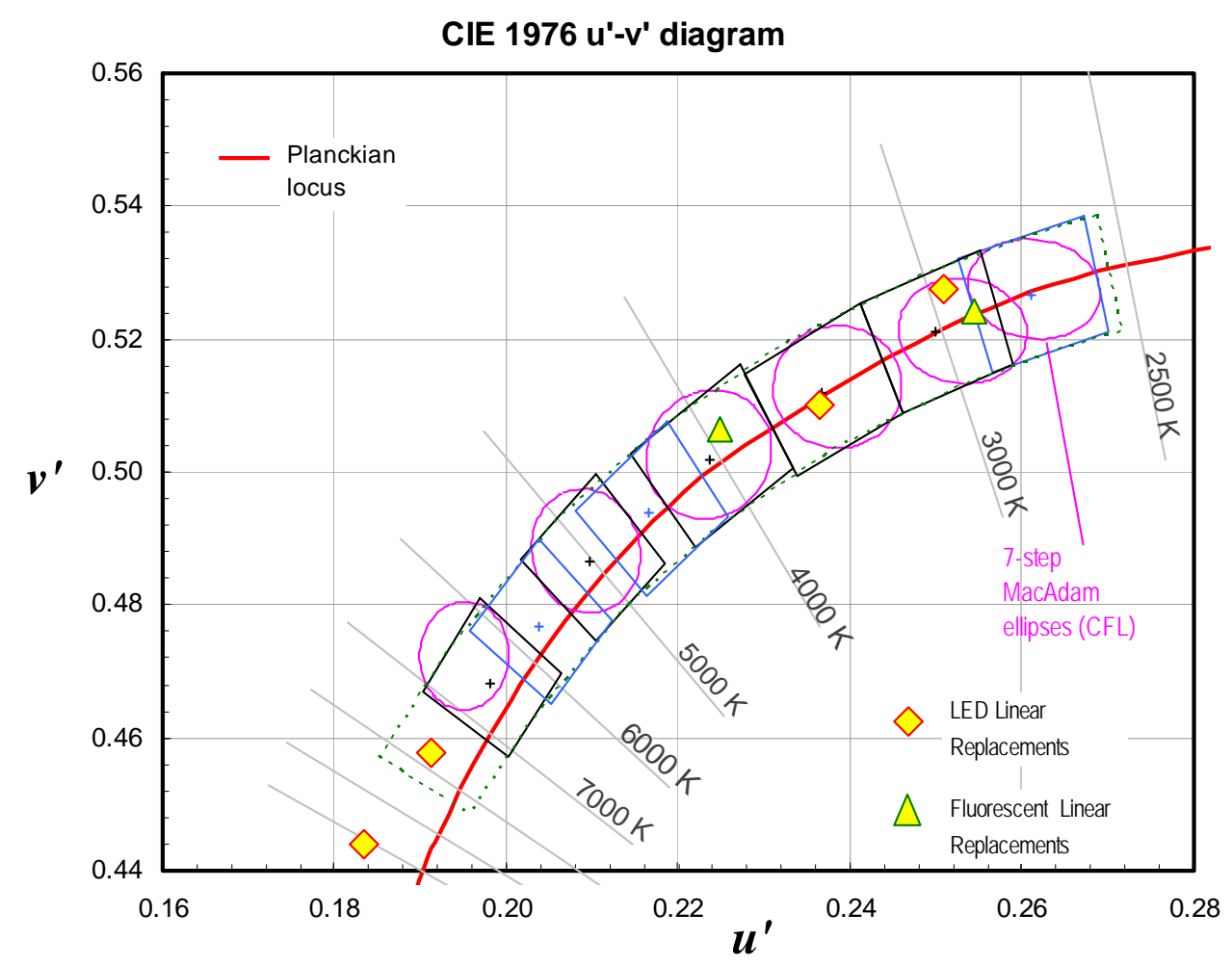

Figure 13. Chromaticity of LED Linear Replacement Lamps (shown as diamonds) Plotted Against ANSI Chromaticity Specifications (chromaticity diagram from ANSI C78.377-2008)

\section{Power}

The power factor of a light source is an indicator of how efficiently a load uses the current that it draws from an AC power system. For example, an incandescent lamp has a power factor of 1.0, which describes a state in which all input power is used by the lamp in producing output (i.e., light and heat). Both fluorescent and LED systems consist of components independent of the light source (e.g., ballasts, power supplies, and other electronic components) that consume both reactive and harmonic power in addition to the power used to produce light, which can result in a power factor of less than 1.0. To encourage efficient use of power in LED products, the ENERGY STAR ${ }^{\circledR}$ program requires power factors greater than 0.7 and 0.9 for residential and commercial applications, respectively, for SSL products. ${ }^{10}$ In CALiPER testing, none of the LED linear replacement lamps met the minimum ENERGY STAR commercial power factor requirement of 0.9 , and only two of the four tested LED products complied with the lower residential power factor requirement (Table 4).

As shown in Tables 4 and 5, LED replacement lamp systems generally use much less power than fluorescent systems - at the expense of light output. To maintain existing illumination levels, it would be

${ }^{10}$ ENERGY STAR power factor requirements are found in "ENERGY STAR Program Requirements for Solid State Lighting Luminaires, Eligibility Criteria - Version 1.0" (2007), available at http://www.energystar.gov/ia/partners/prod_development/new_specs/downloads/SSL_FinalCriteria.pdf. 
necessary to add more LED lamps and/or fixtures, quickly negating any potential energy savings over an existing fluorescent installation.

\section{Performance in 2-ft by 2-ft Troffers}

The CALiPER program has not yet performed comparative in situ testing of troffer systems of other sizes. However, two LED products intended to replace 2-ft by 2-ft troffers have been CALiPER-tested. These two products are integral replacement luminaires, as opposed to replacement lamps intended to be installed in existing 2-ft by 2 -ft troffers. As "purpose-built" LED luminaires, these products may more effectively take advantage of LED chip directionality and integrate more effective thermal management to optimize LED performance. Furthermore, because the overall luminaire efficacy of 2- $\mathrm{ft}$ by 2 -ft fluorescent systems is, on average, less than the efficacy of 2-ft by 4-ft troffers, LED products may be more competitive with these smaller troffers.

Table 7 summarizes the performance of two CALiPER-tested 2-ft by 2-ft recessed panels compared to benchmark data for a typical parabolic louver 2-ft by 2-ft troffer equipped with two 17-W T8 fluorescent lamps (from manufacturer photometric data). Although the two LED samples both draw more power than the fluorescent example, they also produce considerably more light output and have greater efficacy than the fluorescent system. Color characteristics of the LED samples are similar to those of the fluorescent. Light distribution of one of the LED samples is somewhat narrower than the fluorescent example. The other LED sample has somewhat wider distribution than the fluorescent.

Table 7. Performance of 2-ft by 2-ft LED Panels

\begin{tabular}{|c|c|c|c|c|c|}
\hline \multirow[b]{2}{*}{ Fixtures Tested } & \multicolumn{5}{|c|}{ Performance } \\
\hline & $\begin{array}{c}\text { Total } \\
\text { Lamp } \\
\text { Lumens }\end{array}$ & $\begin{array}{c}\text { Total } \\
\text { Luminaire } \\
\text { Lumens }\end{array}$ & $\begin{array}{c}\text { Luminaire } \\
\text { Input Power } \\
\text { (W) }\end{array}$ & $\begin{array}{c}\text { Fixture } \\
\text { Efficiency } \\
(\%)\end{array}$ & $\begin{array}{c}\text { Luminaire } \\
\text { Efficacy } \\
(\mathrm{lm} / \mathrm{W})\end{array}$ \\
\hline Fluorescent benchmark $^{(\mathrm{a})}$ & 2800 & 1384 & 34 & 49 & 41 \\
\hline CALiPER Test ID 08-29 & - & 3313 & 73 & - & 46 \\
\hline CALiPER Test ID 08-61 LFT & - & 3228 & 47 & - & 70 \\
\hline
\end{tabular}

The overall luminaire efficacy of the higher performing LED sample, at $70 \mathrm{~lm} / \mathrm{W}$, is higher than the average luminaire efficacy of the 252 -ft by 4 -ft parabolic louver troffers surveyed for this report (see Table 1), showing great potential for this application of LED technology.

The higher levels of light output and power of these LED samples would imply that direct replacement with fluorescent 2-ft by 2-ft panels could lead to overlighting and greater energy use. However, a lighting system designed specifically for these products could achieve energy savings. 


\section{Untangling Performance Claims for LED Linear Replacement Lamps}

Light-emitting diode replacements for linear fluorescent lamps are generally accompanied by various manufacturer claims regarding energy savings and long life. However, standardized photometric data typically are lacking for these products, and manufacturer claims for light output can be confusing. Some manufacturers provide rated lumen values, and others make claims about achievable illumination levels, such as central lux at a specified distance (e.g., "60 lx/3 m"). Although many manufacturers acknowledge the directional nature of LED linear replacement lamps, it is still difficult to predict product performance without more detailed intensity distribution data.

How then does a consumer untangle confusing manufacturer claims and make useful predictions about LED linear replacement lamp performance? The CALiPER test data in this benchmark report allow for several general predictions:

- Current 4-ft LED linear replacement lamps produce significantly fewer lumens than typical 4-ft T12 and T8 fluorescent lamps, with lower lamp efficacy.

- In situ light output and efficacy for installed LED replacements will be lower than their rated values, due to thermal effects and fixture inefficiencies (as is typically the case for fluorescent lamps).

- Luminaire light output for 2-ft by 4-ft, two-lamp lensed and parabolic louver troffers can be roughly estimated as $85 \%$ of total LED replacement lamp light output (i.e., $85 \%$ fixture efficiency).

Measured luminaire light output for fluorescent troffers equipped with LED replacement lamps was less than $50 \%$ of that with fluorescent lamps, which would result in significantly lower illumination levels in retrofit applications.

Whether a manufacturer characterizes LED linear replacement lamps in terms of lumen output or "central lux," it can be assumed that no more than $85 \%$ of rated lamp light output will leave the troffer. Therefore, a troffer with two LED replacement lamps rated at $1050 \mathrm{~lm}$ each may deliver an estimated $1785 \mathrm{~lm}$ total (i.e., 2 lamps x $1050 \mathrm{~lm} / \mathrm{lamp}$ x 85\% fixture efficiency). Total fixture lumens could then be incorporated into illumination calculations (e.g., lumen method) to estimate average light levels within a space. Unfortunately, manufacturer performance claims in many cases are highly overstated — often based on the individual LED chip performance that manufacturers then incorrectly multiply by the number of chips to determine an estimate for the overall lumen output of their linear replacement lamp. Manufacturers should use photometric reports from testing performed by independent testing laboratories to establish their product ratings. Discerning buyers should request these photometric reports to improve their chances of having reliable performance data.

For LED replacement lamps characterized by illumination levels (e.g., central lux), it can be assumed that light levels below a fixture are proportional also to fixture efficiency. For example, an LED replacement lamp that produces $60 \mathrm{~lx}$ at $3 \mathrm{~m}$ below the lamp would produce $85 \%$ of the rated illumination level when installed in a troffer; that is, $60 \mathrm{~lx} \times 85 \%$ fixture efficiency $=51 \mathrm{~lx}$ at $3 \mathrm{~m}$. For estimation, the central illumination from two LED replacement lamps in one fixture is assumed as additive; for example, $51 \mathrm{~lx} / \mathrm{lamp}$ x 2 lamps $=102 \mathrm{~lx}$ at $3 \mathrm{~m}$ (which would correspond to a very low output from a troffer). Note that this estimated light level has not been adjusted for actual distance from the fixture to the workplane 
and does not include contributions from surrounding fixtures. Again, buyers should be aware of such limited, imprecise performance information and should request complete photometric reports from testing conducted by independent laboratories.

Both estimation methods are crude and are based on rated light outputs that may be overstated by the manufacturer. Absent intensity distribution data, it is also difficult to estimate illumination uniformity, although CALiPER test data indicate that LED linear replacement lamps produce narrower fixture light distributions than fluorescent lamps, which would result in less uniformity in retrofit applications. Equipped with this information, however, a consumer may still be able to roughly estimate the performance of LED linear replacement lamps in fluorescent troffers.

\section{Conclusions}

CALiPER testing of currently available LED replacements for 4-ft T12 and T8 fluorescent lamps indicates a significant performance gap between the two technologies. Light-emitting diode linear replacement lamps are marketed as one-for-one drop-in retrofits for general fluorescent applications; however, their comparatively low light output could result in unacceptably low illumination levels in retrofit applications. To maintain existing light levels, it would be necessary to install additional LED replacement lamps, thereby diminishing potential energy savings and requiring additional fixtures or fixture modifications.

CALiPER tested both fluorescent lamp-ballast systems and LED linear replacement lamps in typical 2-ft by 4-ft, two-lamp lensed and parabolic louver troffers. Troffers are designed to redirect the omnidirectional light output of linear fluorescent lamps downward into a space, with sufficient spread to provide good illumination uniformity. Some light is trapped in the fixture, potentially resulting in low fixture efficiency. LED linear replacements are more directional sources and achieved higher fixture efficiencies than benchmark fluorescent configurations in CALiPER testing. However, low lumen output and efficacy limited their overall performance to levels significantly below those of fluorescent systems. Troffers fitted with the LED replacement products also exhibited narrower light distribution, which could compromise illumination uniformity in existing installations.

Several other characteristics could potentially hamper LED linear replacement lamps in retrofit applications. Of the four LED products tested, three required bypassing the existing fluorescent ballast to connect directly to a line voltage circuit, which would require additional labor (and expense) when retrofitting fixtures. In addition, two of the four LED replacements had a very cool color appearance, with measured CCT values exceeding applicable ANSI tolerances (e.g., >7000 K). Given that many fluorescent installations have a more neutral color appearance (i.e., CCT $3500 \mathrm{~K}-4100 \mathrm{~K}$ ), these noncompliant LED products would not integrate well with existing lighting systems.

It should be noted that fluorescent lighting systems are not free of performance issues, including diminished light output, efficacy, and starting problems at low temperatures, as well as disposal issues related to their mercury content. Consequently, there may be some niche applications where the lower light output and superior cold-temperature operation of LED linear replacements are indicated — with the added benefit of potentially longer life and reduced maintenance. In the meantime, LED technology is 
not yet ready to displace linear fluorescent lamps as replacement light sources in recessed troffers for general interior lighting.

Recent CALiPER testing of 2-ft by 2-ft integral luminaires indicates that integral LED luminaires may be more ready to compete with linear fluorescent troffer systems. As compared to LED linear replacement lamps, well-designed LED luminaires can more effectively take advantage of LED directionality and can better accommodate LED thermal management to maximize efficacies. In all cases, CALiPER has observed a great range of LED product performance available on the market today. Purchasers and specifiers should be wary of manufacturer performance claims; they also should require complete photometric data on new products and refer to the CALiPER benchmarking data to make informed comparisons.

\section{Bibliography}

ANSI-NEMA-ANSLG C78.377-2008. American National Standard for Electric Lamps-Specifications for the Chromaticity of Solid State Lighting Products. American National Standard Lighting Group, Washington, D.C.

Columbia Lighting. 2008. Advertisement in Lighting Design + Application $(L D+A)$, p. 63, February 2008.

Columbia Lighting. 2008. http://www.columbialighting.com/welcome.html (January 2009).

GE Lighting. 2006. Lamp Products Catalog, 2006. Publication 25265, GE Lighting, Cleveland, Ohio.

Legion Lighting. 2008. http://www.legionlighting.com/ (January 2009).

Lightolier. 2008. http://www.lightolier.com/home/home-swf.jsp (January 2009).

Lithonia Lighting. 2008. http://www.lithonia.com/ (January 2009).

Osram Sylvania. 2004. Lamp and Ballast Product Catalog 2004. Catalog04, Osram Sylvania, Danvers, Massachusetts.

Philips Lighting Company. 2006. Lamp Specification and Application Guide 2006. SAG-100, Philips Lighting Company, Somerset, New Jersey.

Prudential Ltg. 2009. http://www.prulite.com/ (January 2009).

Rea M (ed). 2000. IESNA Handbook. 9th ed. Illuminating Engineering Society of North America, New York.

U.S. Census Bureau. 2003. Electric Lighting Fixtures: 2001. Current Industrial Reports MA335L(01)1(RV), U.S. Government Printing Office, Washington D.C. 
US Department of Energy. 2007. ENERGY STAR ${ }^{\circledR}$ Program Requirements for Solid State Lighting Luminaires, Eligibility Criteria - Version 1.0. Available at http://www.energystar.gov/ia/partners/ prod development/new specs/downloads/SSL_FinalCriteria.pdf (January 2009).

U.S. Department of Energy. 2007. "LED Measurement Series: Color Rendering Index and LEDs." Available at http://www.netl.doe.gov/ssl/PDFs/ColorRenderingIndex.pdf (January 2009). 


\section{Appendix}

Luminous Intensity, Zonal Lumens, and Fixture Luminance 


\section{Appendix}

\section{Luminous Intensity, Zonal Lumens, and Fixture Luminance}

Using photometric data from CALiPER testing, it is possible to examine troffer light distribution in terms of luminous intensity, relative zonal lumens, and fixture luminance. These metrics typically are provided by luminaire manufacturers to allow comparison of similar products. Similarly, these data can be used to compare troffer performance with fluorescent lamps and LED replacements and illustrate how LED directionality affects fixture light distribution. Figures A.1 through A.8 present luminous intensity distributions and zonal lumen summaries for CALiPER-tested lensed and parabolic louver troffers fitted with fluorescent and LED replacement lamps.

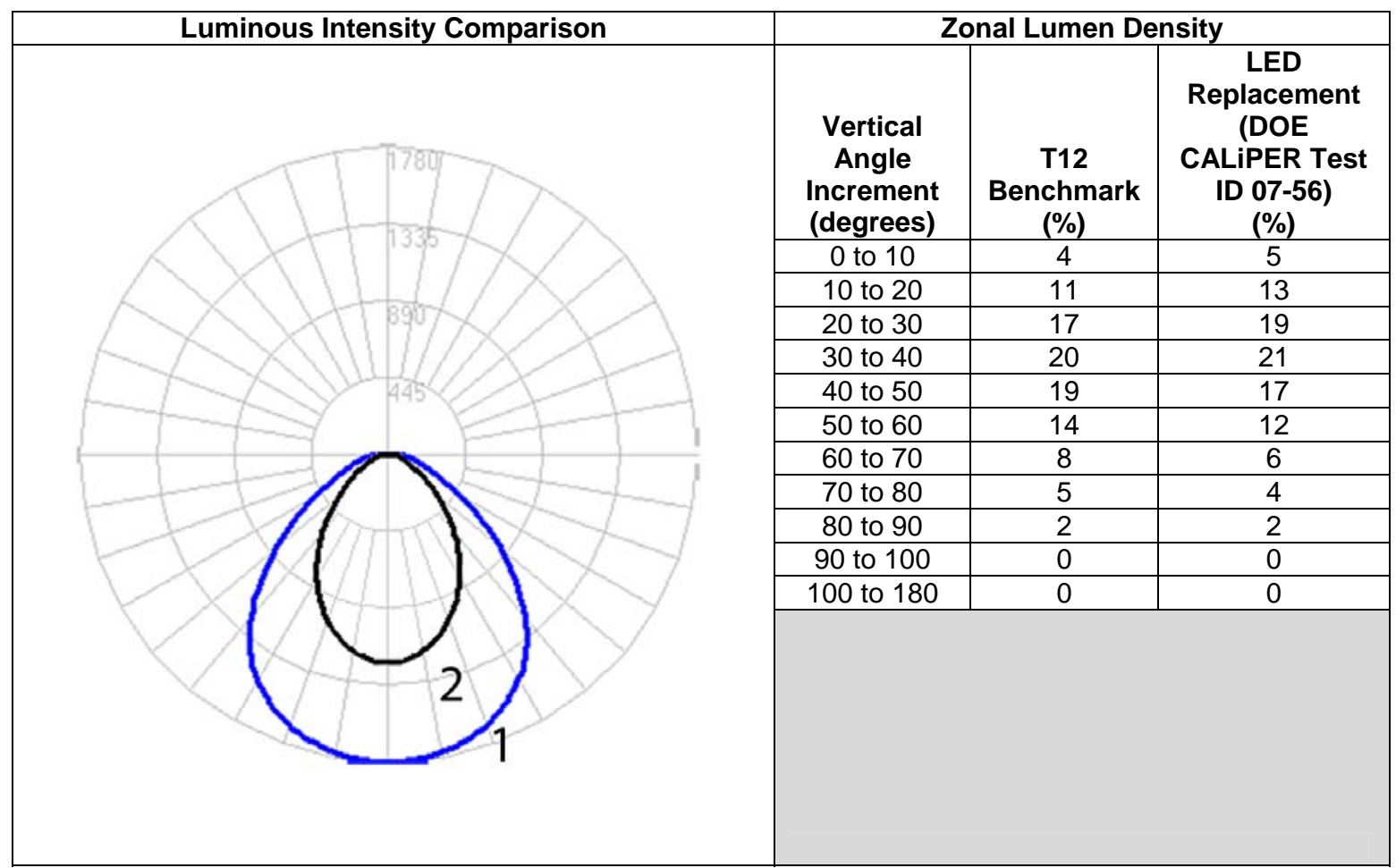

Figure A.1. Lensed Troffer Comparison: Benchmark T12 (Curve 1) and LED Replacement 07-56 (Curve 2) 


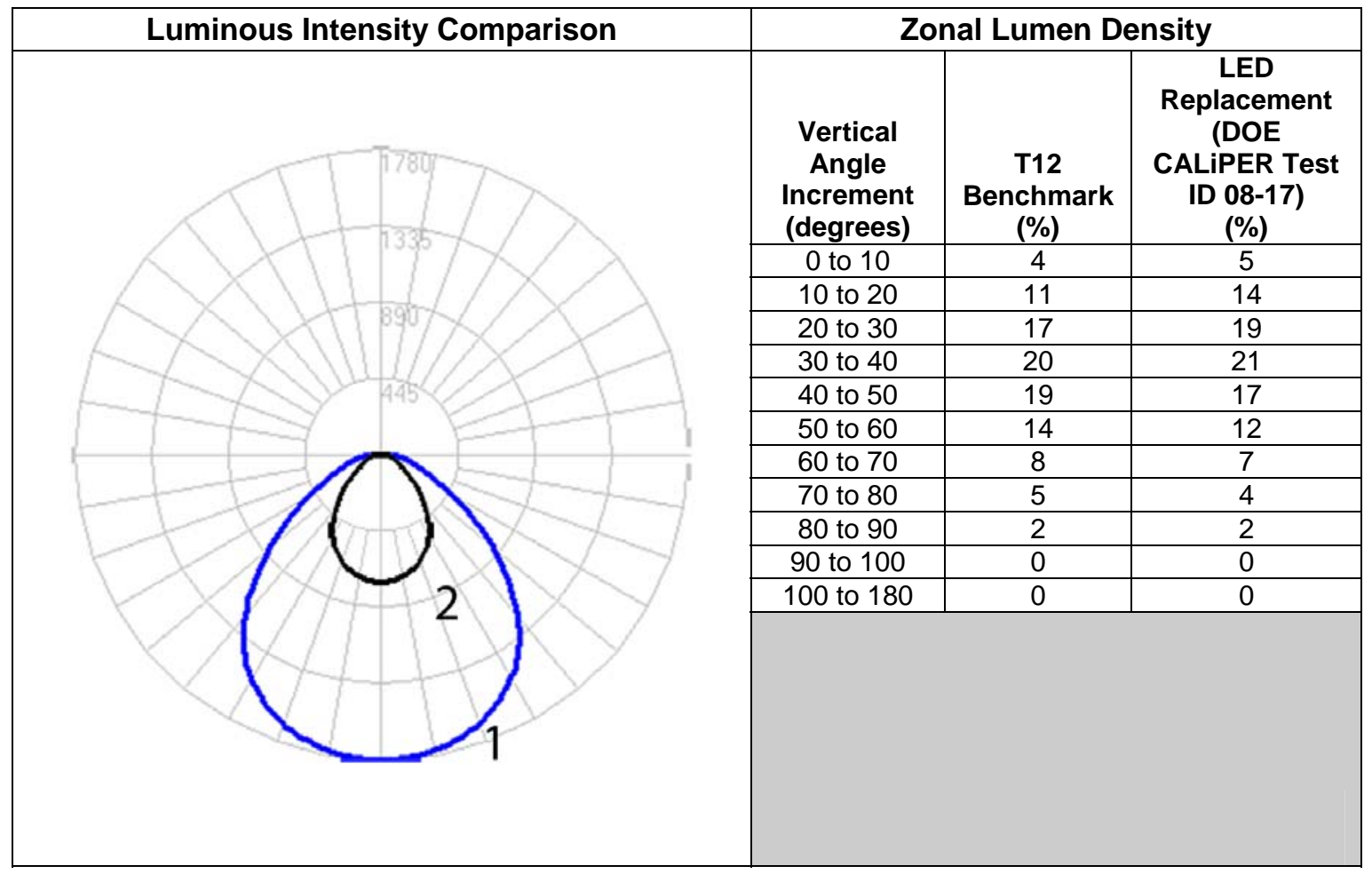

Figure A.2. Lensed Troffer Comparison: Benchmark T12 (Curve 1) and LED Replacement 08-17 (Curve 2)

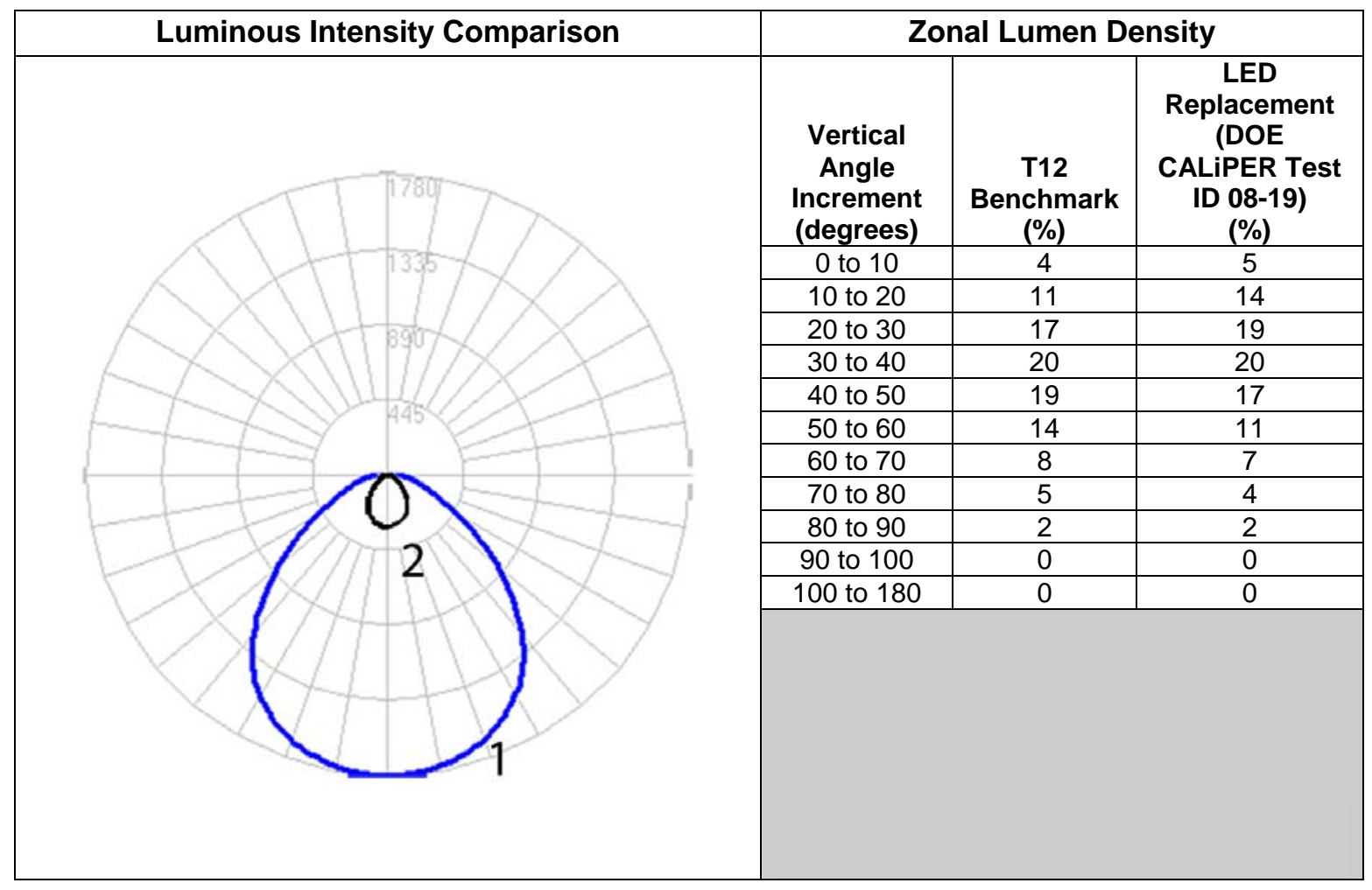

Figure A.3. Lensed Troffer Comparison: Benchmark T12 (Curve 1) and LED Replacement 08-19 (Curve 2) 


\begin{tabular}{|c|c|c|c|}
\hline Luminous Intensity Comparison & \multicolumn{3}{|c|}{ Zonal Lumen Density } \\
\hline & $\begin{array}{l}\text { Vertical } \\
\text { Angle } \\
\text { Increment } \\
\text { (degrees) }\end{array}$ & $\begin{array}{c}\text { T12 } \\
\text { Benchmark } \\
(\%)\end{array}$ & $\begin{array}{c}\text { LED } \\
\text { Replacement } \\
\text { (DOE } \\
\text { CALiPER Test } \\
\text { ID 08-37) } \\
(\%) \\
\end{array}$ \\
\hline & 0 to 10 & 4 & 5 \\
\hline & 10 to 20 & 11 & 13 \\
\hline & 20 to 30 & 17 & 19 \\
\hline & 30 to 40 & 20 & 21 \\
\hline & 40 to 50 & 19 & 18 \\
\hline & 50 to 60 & 14 & 12 \\
\hline & 60 to 70 & 8 & 6 \\
\hline & 70 to 80 & 5 & 4 \\
\hline & 80 to 90 & 2 & 2 \\
\hline & $\frac{9010100}{100 \text { to } 180}$ & 0 & 0 \\
\hline & & & \\
\hline & & & \\
\hline & & & \\
\hline & & & \\
\hline
\end{tabular}

Figure A.4. Lensed Troffer Comparison: Benchmark T12 (Curve 1) and LED Replacement 08-37 (Curve 2)

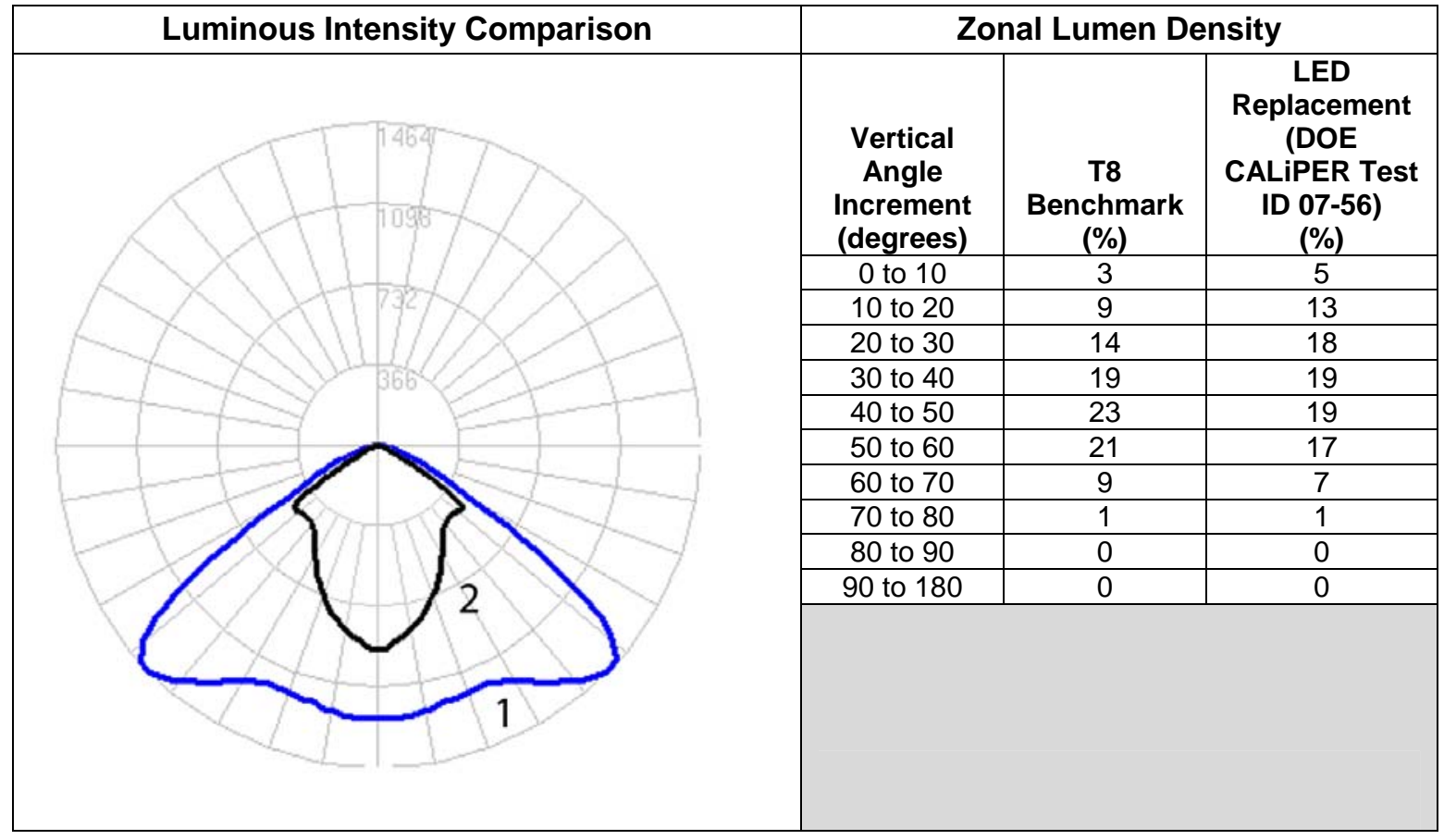

Figure A.5. Parabolic Louver Troffer Comparison: Benchmark T8 (Curve 1) and LED Replacement 07-56 (Curve 2) 


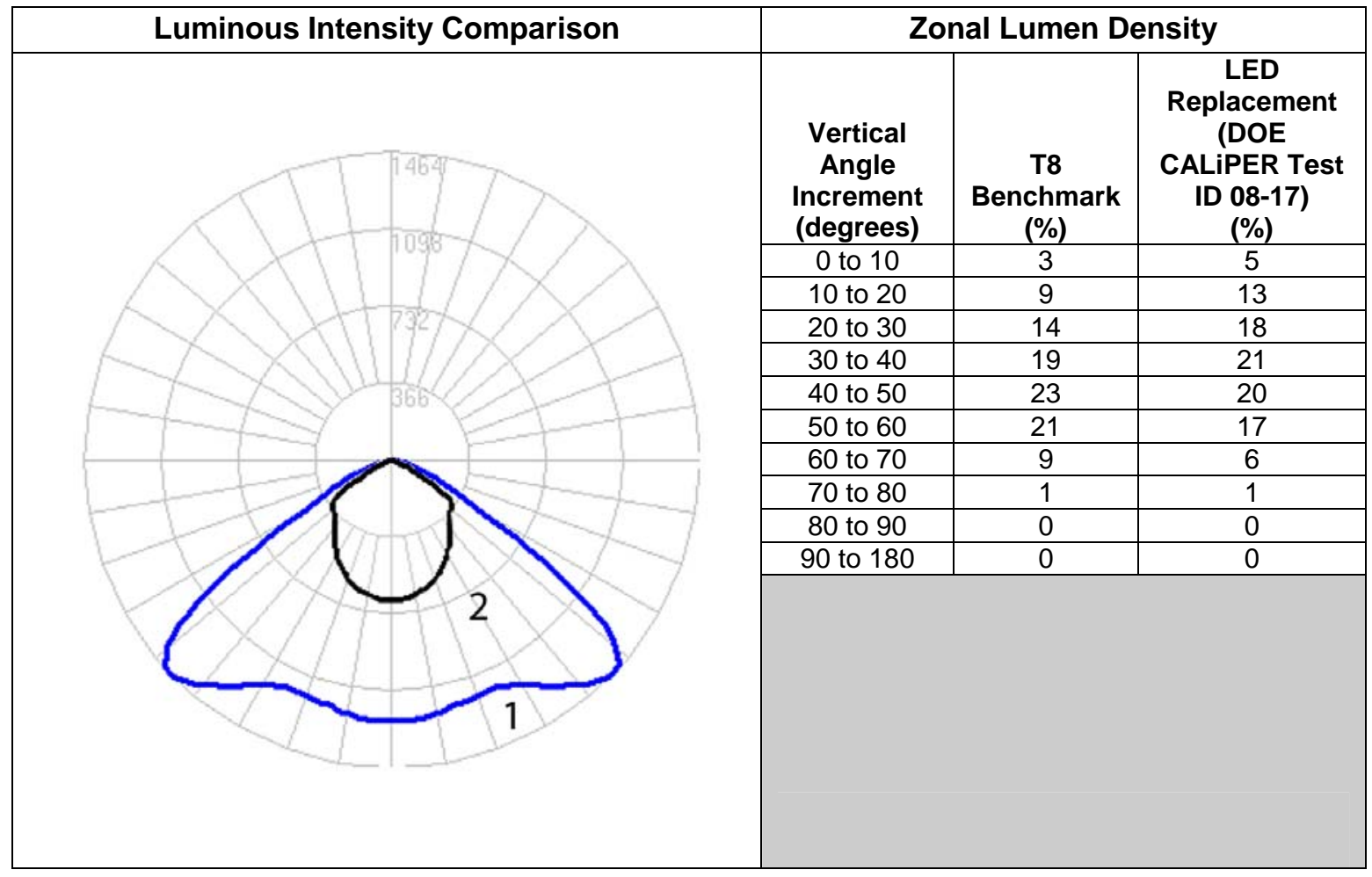

Figure A.6. Parabolic Louver Troffer Comparison: Benchmark T8 (Curve 1) and LED Replacement 0817 (Curve 2)

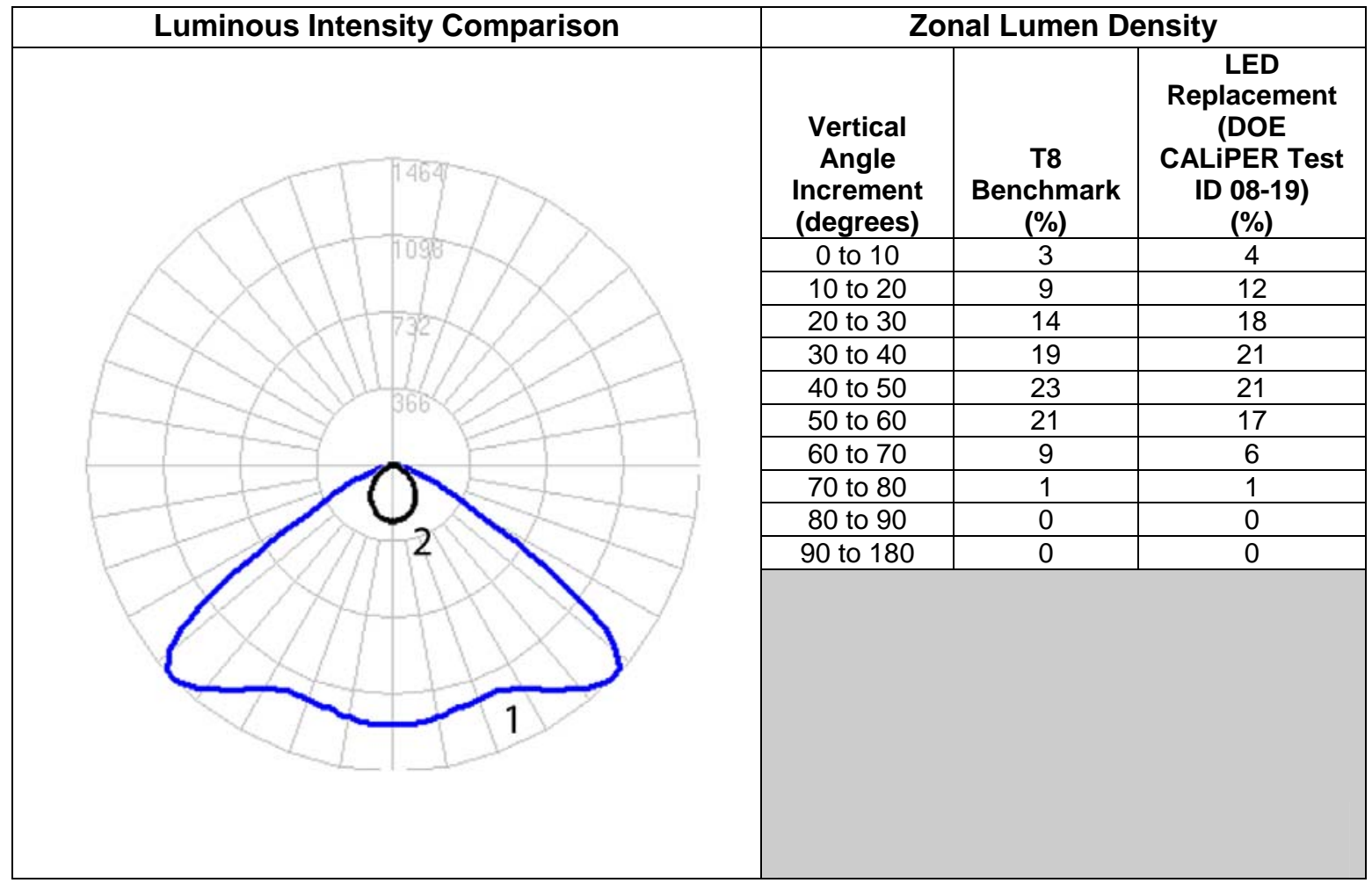

Figure A.7. Parabolic Louver Troffer Comparison: Benchmark T8 (Curve 1) and LED Replacement 08-19 (Curve 2) 


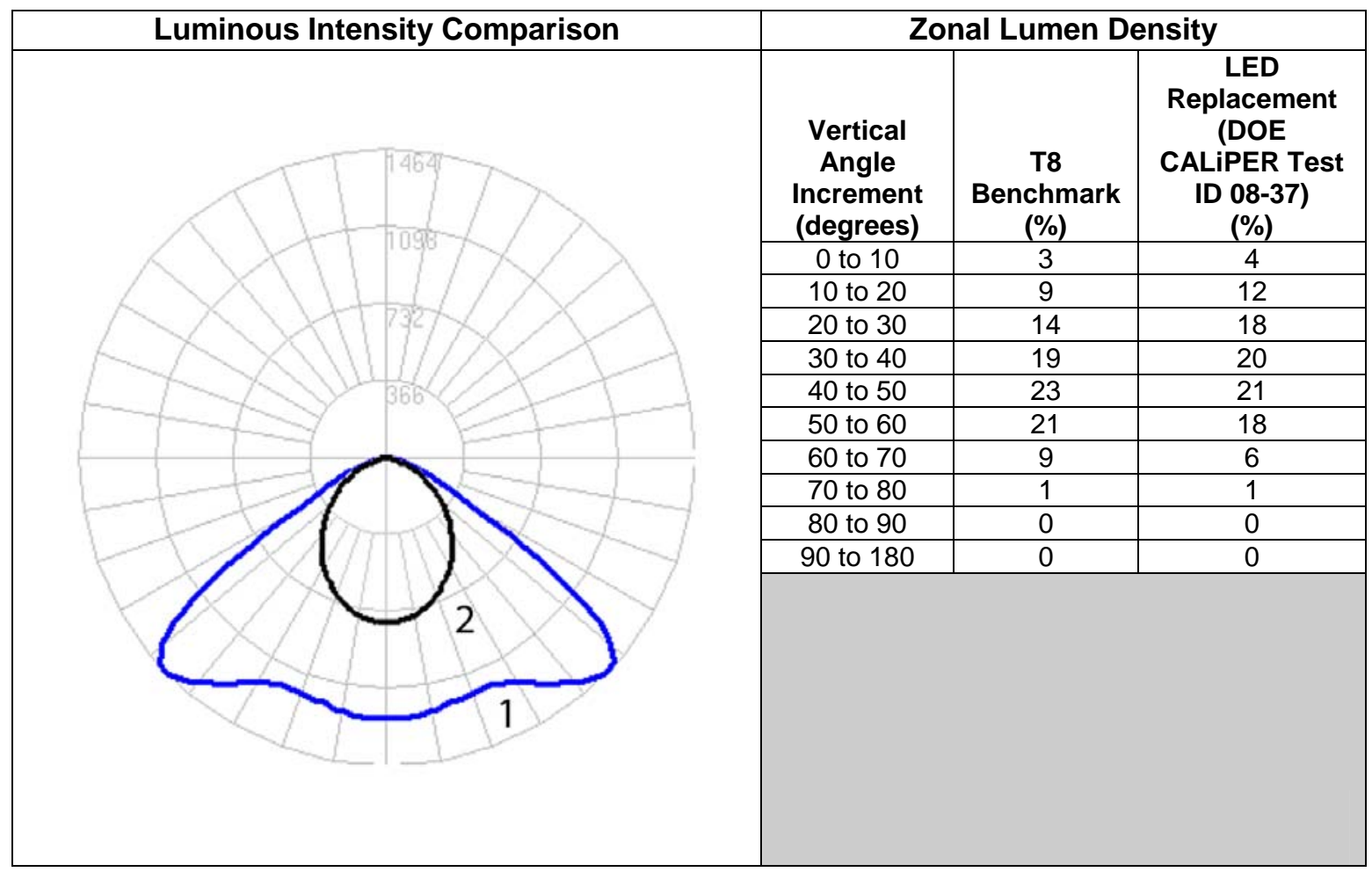

Figure A.8. Parabolic Louver Troffer Comparison: Benchmark T8 (Curve 1) and LED Replacement 08-37 (Curve 2) 
Fixture luminance data help predict perceived brightness (and glare potential) of a luminaire at various vertical and lateral angles. Table A.1 presents the luminance for the various replacements lamps tested in the same troffers at $0^{\circ}$ lateral angle (along the length of the fixture; results at $45^{\circ}$ and at $90^{\circ}$ lateral angles are similar).

Table A.1. Luminance Comparison for Lensed and Parabolic Louver Troffers

\begin{tabular}{|c|c|c|c|c|}
\hline \multicolumn{5}{|c|}{ Lensed Troffer Luminance Data at $0^{\circ}$ Lateral Angle } \\
\hline \multirow[t]{2}{*}{$\begin{array}{l}\text { Vertical Angle } \\
\text { (in degrees) }\end{array}$} & \multirow{2}{*}{ 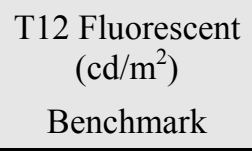 } & \multicolumn{3}{|c|}{$\begin{array}{l}\text { LED Linear Replacement Lamps } \\
\qquad\left(\mathrm{cd} / \mathrm{m}^{2}\right)\end{array}$} \\
\hline & & Average & Minimum & Maximum \\
\hline 0 & 2874 & 1011 & 499 & 1950 \\
\hline 45 & 2279 & 597 & 309 & 1067 \\
\hline 55 & 1738 & 420 & 216 & 741 \\
\hline 65 & 1318 & 306 & 161 & 557 \\
\hline 75 & 1432 & 350 & 182 & 635 \\
\hline 85 & 1399 & 368 & 196 & 699 \\
\hline \multicolumn{5}{|c|}{ Parabolic Louver Troffer Luminance Data at $0^{\circ}$ Lateral Angle } \\
\hline \multirow[t]{2}{*}{$\begin{array}{l}\text { Vertical Angle } \\
\text { (in degrees) }\end{array}$} & $\begin{array}{l}\text { T8 Fluorescent } \\
\left(\mathrm{cd} / \mathrm{m}^{2}\right)\end{array}$ & \multicolumn{3}{|c|}{$\begin{array}{l}\text { LED Linear Replacement Lamps } \\
\qquad\left(\mathrm{cd} / \mathrm{m}^{2}\right)\end{array}$} \\
\hline & Benchmark & Average & Minimum & Maximum \\
\hline 0 & 2071 & 882 & 447 & 1543 \\
\hline 45 & 1906 & 585 & 329 & 966 \\
\hline 55 & 1736 & 448 & 241 & 767 \\
\hline 65 & 1172 & 234 & 115 & 423 \\
\hline 75 & 230 & 52 & 28 & 92 \\
\hline 85 & 0 & 882 & 447 & 1543 \\
\hline
\end{tabular}

Fixture luminance typically is not used as a predictor of light output or resulting light levels and uniformity. However, fixture luminance is indicative of luminous intensity and further illustrates the significant difference in intensity distribution (and, by extension, lumen output) between the fluorescent and LED replacement configurations. 